ISSN 2072-4292

www.mdpi.com/journal/remotesensing

Article

\title{
Ice Freeze-up and Break-up Detection of Shallow Lakes in Northern Alaska with Spaceborne SAR
}

\section{Cristina M. Surdu ${ }^{1,2, *}$, Claude R. Duguay ${ }^{2}$, Homa Kheyrollah Pour ${ }^{2}$ and Laura C. Brown ${ }^{3}$}

1 Earth Observation/Science, Applications and Future Technologies Department, European Space Agency (ESA), 00044 Frascati, Italy

2 Department of Geography and Environmental Management, and Interdisciplinary Centre on Climate Change, University of Waterloo, Waterloo, ON N2L 3G1, Canada;

E-Mails: crduguay@uwaterloo.ca (C.D.); h2kheyro@uwaterloo.ca (H.P.)

3 Department of Geography, University of Toronto Mississauga, Mississauga, ON L5L 1C6, Canada; E-Mail: lc.brown@utoronto.ca

* Author to whom correspondence should be addressed; E-Mail: cristina.surdu@esa.int; Tel.: +39-06-9418-0629; Fax: +39-06-9418-0602.

Academic Editors: Richard Gloaguen and Prasad S. Thenkabail

Received: 13 January 2015 / Accepted: 5 May 2015 / Published: 18 May 2015

Abstract: Shallow lakes, with depths less than ca. 3.5-4 m, are a ubiquitous feature of the Arctic Alaskan Coastal Plain, covering up to $40 \%$ of the land surface. With such an extended areal coverage, lakes and their ice regimes represent an important component of the cryosphere. The duration of the ice season has major implications for the regional and local climate, as well as for the physical and biogeochemical processes of the lakes. With day and night observations in all weather conditions, synthetic aperture radar (SAR) sensors provide year-round acquisitions. Monitoring the evolution of radar backscatter $\left(\sigma^{\circ}\right)$ is useful for detecting the timing of the beginning and end of the ice season. Analysis of the temporal evolution of C-band $\sigma^{\circ}$ from Advanced Synthetic Aperture Radar (ASAR) Wide Swath and RADARSAT-2 ScanSAR, with a combined frequency of acquisitions from two to five days, was employed to evaluate the potential of SAR to detect the timing of key lake-ice events. SAR observations from 2005 to 2011 were compared to outputs of the Canadian Lake Ice Model (CLIMo). Model simulations fall within similar ranges with those of the SAR observations, with a mean difference between SAR observations and model simulations of only one day for water-clear-of-ice (WCI) from 2006 to 2010. For freeze onset (FO), larger mean differences were observed. SAR analysis shows that the mean FO date for these 
shallow coastal lakes is 30 September and the mean WCI date is 5 July. Results reveal that greater variability existed in the mean FO date (up to 26 days) than in that of melt onset (MO) (up to 12 days) and in that of WCI (6 days). Additionally, this study also identifies limitations and provides recommendations for future work using C-band SAR for monitoring the lake-ice phenology of shallow Arctic lakes.

Keywords: Arctic lakes; break-up; freeze onset; synthetic aperture radar

\section{Introduction}

Freshwater lakes are a prevailing feature of the Arctic landscape. In the lake-rich coastal Northern Alaskan tundra, shallow thermokarst lakes cover up to $40 \%$ of the land area [1,2]. During recent decades (1991-2011), these lakes have experienced a shift from a grounded-ice to a floating-ice regime-with $22 \%$ less lakes freezing to the lakebed, thinner ice covers by $21-38 \mathrm{~cm}$, and shorter ice seasons as a result of later ice-on dates by 14.5 days and earlier WCI (ice-off) dates by 5.3 days [3]. In an Arctic climate that experiences increasing surface air temperatures [4,5], higher amounts of snowfall from October to May (1936-2009) in most regions [6], reduced snow cover duration (by 3.9 days per decade (1972-2008); [6]) and decreased spring snow cover extent (by 14\% in May and 46\% in June, from 1967 to 2008; [7]), thaw lakes are undergoing noticeable changes $[3,8]$.

Changes in the ice cover of these Arctic lacustrine ecosystems impact the underlying permafrost by promoting thaw of formerly perennially frozen sediment and leading to talik development, as a result of a regime shift from grounded to floating ice [9]. Thinner ice covers, earlier timing of lake WCI dates, and longer open-water seasons influence summer-water temperature, lake-water balance, aquatic biota, and water availability for residential and industrial use. The overall shorter ice seasons of lakes on the Alaskan North Slope [3] may also impact ice-road transportation in the region during winter. If the recently investigated changes continue it is anticipated that Alaska will lose $29 \%$ of its ice roads by 2050 [10].

The ice cover of Arctic lakes has been identified to be very responsive to near-surface air temperatures, particularly during the break-up season [11]. Given the bathymetry-related reduced heat capacity of smaller and shallower lakes, the response of these lakes to changes in air temperatures is fast. Lakes on the coastal North Slope of Alaska (NSA) are strongly reflecting this sensitivity [12].

Previous studies showed that even though both complete-freeze-over and WCI dates are highly synchronous with the $0^{\circ} \mathrm{C}$ fall and spring isotherm dates, a stronger correlation exists between the timing of WCI dates and surface air temperatures [13]; lake-ice decay is sensitive to synoptic weather conditions [14], including changes in air temperature, snow and/or wind. The effect of air temperature on lake ice is smaller during freeze-up than it is during break-up, as freeze-up is also dependent on lake morphometry (depth, area and volume), wind speed, and non-climatic variables such as elevation or latitude. Recent warming at higher latitudes is likely to result in later FO and earlier WCI dates for lakes across the Arctic.

Lake-ice phenology has been investigated with both optical and SAR data. Given the limitations associated with detection of freeze-up timing, past studies mainly focused on timing of break-up. Ice-out timing for lakes across Alaska from 2007 to 2012 was investigated with MODIS ([15]. Limited by the coarse spatial resolution (e.g., 250-500 $\mathrm{m}$ for MODIS optical data), low sun elevation and presence of 
the cloud cover, optical sensors do not allow lake-ice monitoring year round at high latitudes. To overcome these limitations, SAR observations provide a feasible alternative. With a history of over two decades, SAR systems have demonstrated their ability to monitor ice phenology of Arctic and sub-Arctic lakes through analysis of the $\sigma^{\circ}$ temporal evolution, at $\mathrm{C}$-band [12,16-23] and $\mathrm{Ku}$-band frequencies [23].

High temporal resolution spaceborne observations are a prerequisite for studying the impact of climate variability and change on Arctic lake-ice covers [24]. Previous satellite missions (e.g., ERS-1/2, ENVISAT, and RADARSAT-1/2) alone did not provide the required high temporal frequency. This work is the first attempt to combine SAR observations from two different satellite sensors to detect ice phenological events on shallow Arctic lakes. The primary purpose of this study is to explore the potential of high temporal frequency (2-5 days) C-band SAR to detect lake-ice events, in light of future Earth Observation satellite missions that will provide frequent acquisitions at high latitudes. More specifically, the objectives of this study are: (1) to evaluate the ability of combined ENVISAT ASAR and RADARSAT-2 observations for detecting the timing of the initial ice formation (FO), beginning of melt (MO) and end of the ice season (WCI) of shallow lakes in a sub-region of the Alaskan Arctic Coastal Plain by employing an ice phenology algorithm based on "tracking" of the temporal evolution of $\sigma^{\circ}$; (2) to analyze the temporal variability in ice phenology from 2005 to 2011 of lakes, with overlapping observations between 2009-2011 prior to the end of the ENVISAT mission in early 2012; and (3) to assess SAR-observed lake-ice parameters against results obtained with a numerical lake-ice model.

\section{Study Area}

The lakes of interest are located in the vicinity of Barrow, on the North Slope of Alaska (NSA), USA, $\left(71^{\circ} 31^{\prime} \mathrm{N}, 156^{\circ} 45^{\prime} \mathrm{W}\right)$, a coastal region bounded by ocean waters to the west (Chukchi Sea), north and east (Beaufort Sea) (Figure 1). Thermokarst lakes, mostly shallow ( $\sim 3 \mathrm{~m}$ deep), are the predominant feature of the region and lie atop a continuous permafrost layer. The ice cover of these lakes, many of which freeze entirely to the lakebed during winter, has been observed to be present for the most part of the year, as the lakes are ice free for 6-16 weeks during the warmer summer months [12,16]. From 2005 to 2011, recorded annual mean air temperature at Barrow was $-10^{\circ} \mathrm{C}$ and mean annual precipitation was $1,545 \mathrm{~mm}$. 


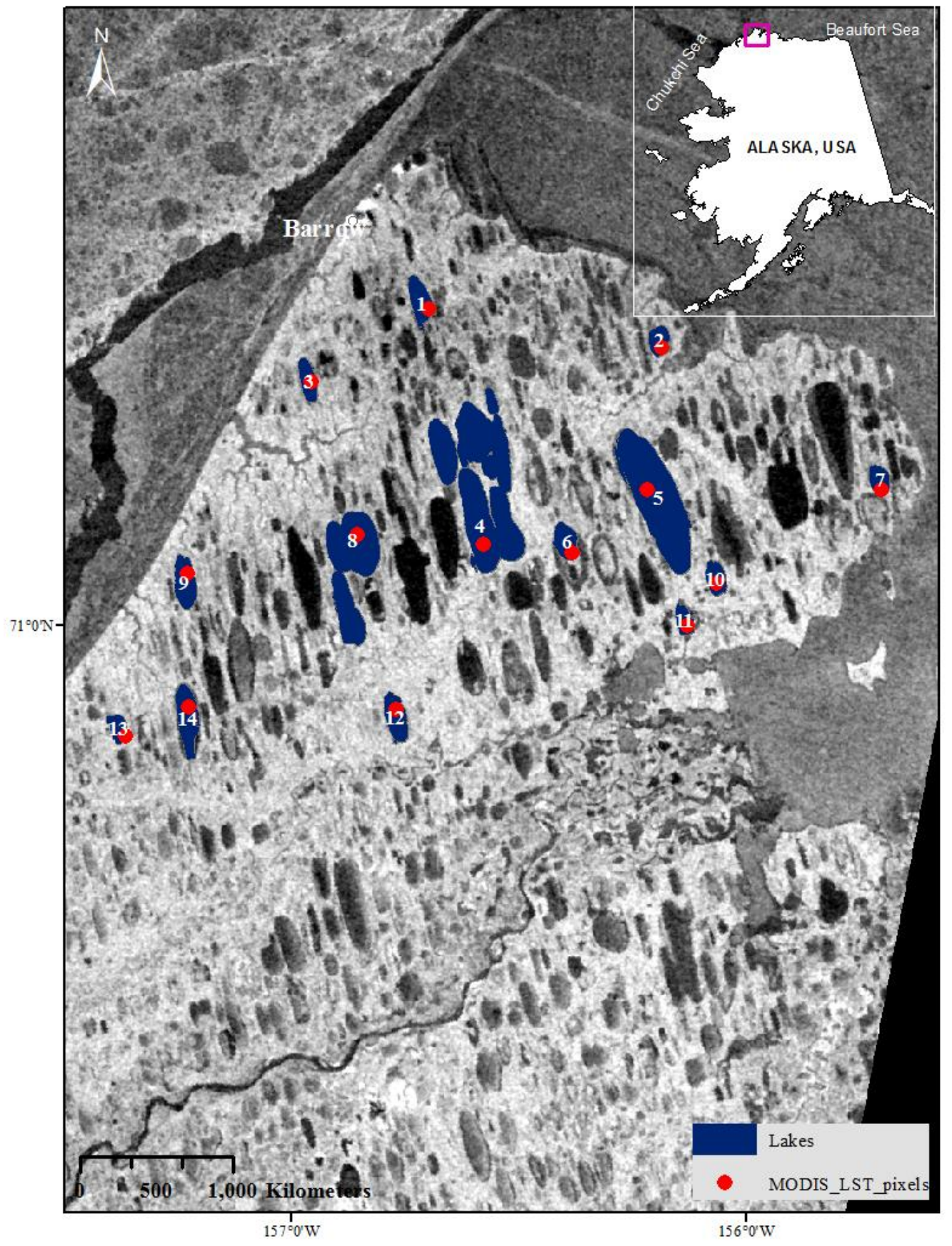

Figure 1. Map of the Alaskan North Slope, near Barrow, indicating the location of study lakes (dark blue) and the MODIS pixels used for extraction of lake surface water/ice surface temperature (red). The 5 June 2009 ASAR image is copyright ESA.

\section{Data and Methods}

\subsection{Synthetic Aperture Radar (SAR)}

This study used available C-band time series of ASAR Wide Swath (2005-2011) and RADARSAT-2 ScanSAR Wide A (2009-2011) images. While the RADARSAT-2 mission continues to deliver data, the ENVISAT mission carrying the C-band ASAR sensor ceased in April 2012. The overlapping ASAR and RADARSAT-2 observation period (2009-2011) provides a higher temporal sampling frequency (2-5 days) 
than from a single satellite mission, thus enabling a more precise detection of lake ice events. Ascending and descending, HH-polarized ASAR acquisitions were used from 2005 to 2011 (536 scenes). In order to maximize the temporal frequency, overlapping HH-polarized RADARSAT-2 observations from 2009 to 2011 (213 acquisitions) were also included in the analysis.

To avoid false detection of ice parameters because of the relatively low signal-to-noise ratio (reduced icewater contrast) of the HV-RADARSAT-2 imagery [21], $\sigma^{\circ}$ values were solely extracted from HH acquisitions. The two sensors provide observations at a spatial resolution of $\sim 150 \mathrm{~m}$ for ASAR and $100 \mathrm{~m}$ for RADARSAT-2. Pixel spacing is $75 \mathrm{~m} \times 75 \mathrm{~m}$ for ASAR and $50 \mathrm{~m} \times 50 \mathrm{~m}$ for RADARSAT-2. Following radiometric calibration and geocoding of the images using the Next ESA SAR Toolbox (NEST) software, the inherent speckle present in SAR images was reduced using an adaptive Enhanced Lee filter with a kernel size of $3 \times 3$. In order to capture a wide range of lakes with different physical properties and situated in various locations of the NSA — shallow (e.g., West Twin Lake — maximum depth of $1.2 \mathrm{~m}$ )/deep (e.g., Imikpuk Lake - maximum depth of $3.1 \mathrm{~m}$ ) (Mellor, 1982); small/large (e.g., surface area of $2.7 \mathrm{~km}^{2}$ for Unknown Lake I, $5.2 \mathrm{~km}^{2}$ for Ikroavik Lake, $57.7 \mathrm{~km}^{2}$ for Lake Sungovoak); inland/coastal; central/peripheral; eastern/western; northern/southern; and with floating/grounded ice - 14 sample lakes or regions of interest (ROIs) were selected for analysis. The number of pixels within each ASAR/RADARSAT-2 ROI ranged from 290/1,094 to 6,131/23,148 (Table 1). Selection of lakes of different depths was based on previous in situ observations for several lakes in this region [25]. $\sigma^{\circ}$ of selected ROIs was extracted using the Environment for Visualizing Images (ENVI) software, version 5.0. Following $\sigma^{\circ}$ extraction, the median $\sigma^{\circ}$ of each ROI was calculated and used as a unique value for the ice phenological event observed on the date of the SAR acquisition; ranges of dates for important ice events for the 14 lakes were also provided. The terminology used for the purpose of this study applies to the entire surface area of the investigated lakes.

Table 1. List of the 14 sample lakes (regions of interest (ROIs)) and number of ASAR and RADARSAT-2 SAR pixels encompassed in each ROI. Lake type is also shown.

\begin{tabular}{ccccc}
\hline ROI \# & Lake Name & $\begin{array}{c}\text { Number of } \\
\text { ASAR Pixels }\end{array}$ & $\begin{array}{c}\text { Number of } \\
\text { RADARSAT-2 Pixels }\end{array}$ & Lake Type \\
\hline 1 & Ikroavik Lake & 567 & 2098 & coastal/central \\
2 & Unnamed Lake A & 328 & 1224 & coastal/peripheral \\
3 & Unnamed Lake B & 390 & 1442 & northern \\
4 & Lake Sungovoak & 6131 & 23148 & large \\
5 & Lake Tusikvoak & 3833 & 14416 & deep \\
6 & Unnamed Lake C & 465 & 1730 & shallow \\
7 & Unnamed Lake D & 323 & 1234 & western \\
8 & Sukok Lake & 2913 & 10985 & floating ice cover \\
9 & Unnamed Lake E & 622 & 2352 & eastern \\
10 & Unnamed Lake F & 372 & 1410 & inland/peripheral \\
11 & Unnamed Lake G & 299 & 1103 & inland/central \\
12 & Unnamed Lake H & 599 & 2232 & southern \\
13 & Unnamed Lake I & 290 & 1094 & small \\
14 & Tractor Lake & 813 & 3100 & grounded ice cover \\
\hline
\end{tabular}


$\sigma^{\circ}$ was extracted from the 14 SAR ROIs and used to detect the beginning, the onset of melt and the end of the ice season (WCI), by analyzing its temporal evolution. Differences in radiometric calibration of the two SAR sensors result in generally lower RADARSAT- 2 mean $\sigma^{\circ}$ values by $-3.56 \mathrm{~dB}$, likely explained by the differences in incidence angle $(\theta)$ and orbit (ascending and descending) between the images. C-band $\sigma^{\circ}$ between the freeze-up and break-up periods is controlled by ice thickness, snow and/or snow ice, the presence or absence of bubbles (particularly during freeze-up), and by the large difference between the dielectric constant $\left(\varepsilon^{\prime}\right)$ of ice (3.2) and $\varepsilon^{\prime}$ of water $(80)$ [16,22,26].

With C-band, the start of ice formation over lakes is indicated by the first considerable increase in $\sigma^{\circ}$ [27]. FO detection is complicated by the low $\sigma^{\circ}$ contrast between the open water and the newly formed ice [20], by the $\sigma^{\circ}$ sensitivity to wind speed and direction, as well as the ice structure and thickness, roughness of the ice interface, all resulting in higher returns, and snow wetness [22] that results in lower returns. On shallow lakes, the transition from an ice cover with minimum air inclusions (bubbles) at the beginning of the ice season to an ice layer with increased bubble density as ice growth progresses complicates the $\sigma^{\circ}$ analysis during freeze-up. As a result, the $\sigma^{\circ}$ oscillations during ice formation make detection of a continuous ice cover (complete freeze-over) uncertain. Given the limitations associated with deriving an accurate date of complete freeze-over, ice-cover duration, calculated from the date of complete freezeover to the WCI date, was not computed. The current study considers the first significant $\sigma^{\circ}$ up-turn as the FO date for the selected ROIs. Once ice has reached its maximum ice thickness, high radar returns have been observed from a floating ice cover, while grounded ice, or ice frozen to the lakebed, is indicated by low $\sigma^{\circ}[16]$.

MO is identified by the first significant decrease in $\sigma^{\circ}$ given by the presence of water from internal melting of ice and/or a melting snow cover, and thus resulting in increased specular reflection [23,28]. Following initial melt, water drains off the ice surface and leaves a rough surface that results in high radar returns. Thaw and re-freeze events of ice and snow during the break-up period result in high fluctuations of $\sigma^{\circ}$. Low $\sigma^{\circ}$ is observed at the end of the ice season when water becomes clear of ice. High winds over the lake surface can also result in high $\sigma^{\circ}$ during the open-water season. The current analysis acknowledges the differences in $\sigma^{\circ}$ as a result of the wide range of beam positions (incidence angles) but in order to increase the precision in detecting the initial ice decay and end of the ice season through more frequent acquisitions, the analysis includes radar $\sigma^{\circ}$ acquired at all available incidence angles, ranging between $15^{\circ}-42^{\circ}$ for ASAR and $20^{\circ}-46^{\circ}$ for RADARSAT- 2 .

In order to avoid false starts, a threshold is applied to the $\sigma^{\circ}$ values detected during stable ice winter conditions, given by the average of each SAR pixel from 1 January (DOY1) to 31 March (DOY90). For FO, an increase of $5.5 \mathrm{~dB}$ for ASAR, and an increase of $6.5 \mathrm{~dB}$ for RADARSAT- 2 change in $\sigma^{\circ}$ was required to occur for two consecutive dates. This threshold is higher than that selected for MO ( $4 \mathrm{~dB}$ for ASAR and $5 \mathrm{~dB}$ for RADARSAT-2) in order to minimize FO detection errors associated with higher $\sigma^{\circ}$ from wind-roughened cracks, rafting and ridge formation [23]. For detection of WCI conditions, the applied $\sigma^{\circ}$ threshold was a decrease of $7.5 \mathrm{~dB}$ for ASAR and a drop of $8.5 \mathrm{~dB}$ for RADARSAT-2. A similar approach was employed in detection of ice phenology parameters for Great Bear Lake and Great Slave Lake through analysis of the temporal evolution of Ku-band $\sigma^{\circ}[23]$.

In order to evaluate the SAR observations for the detection of WCI dates, segmentation of the available SAR images on the mean WCI date was performed. The unsupervised K-means classification algorithm was used to determine if ice was present on lakes on the date when WCI was indicated by the $\sigma^{\circ}$ analysis. This 
common clustering method provides suitable discrimination between ice and water in SAR imagery during the break-up season [29]. Following subsequent iterations of individual image segmentations, each intensity value is assigned to the class with the nearest arithmetic mean. The final segmentation result provides a two-class map (ice and open water), with fractions (\%) for each class (Figure 2).
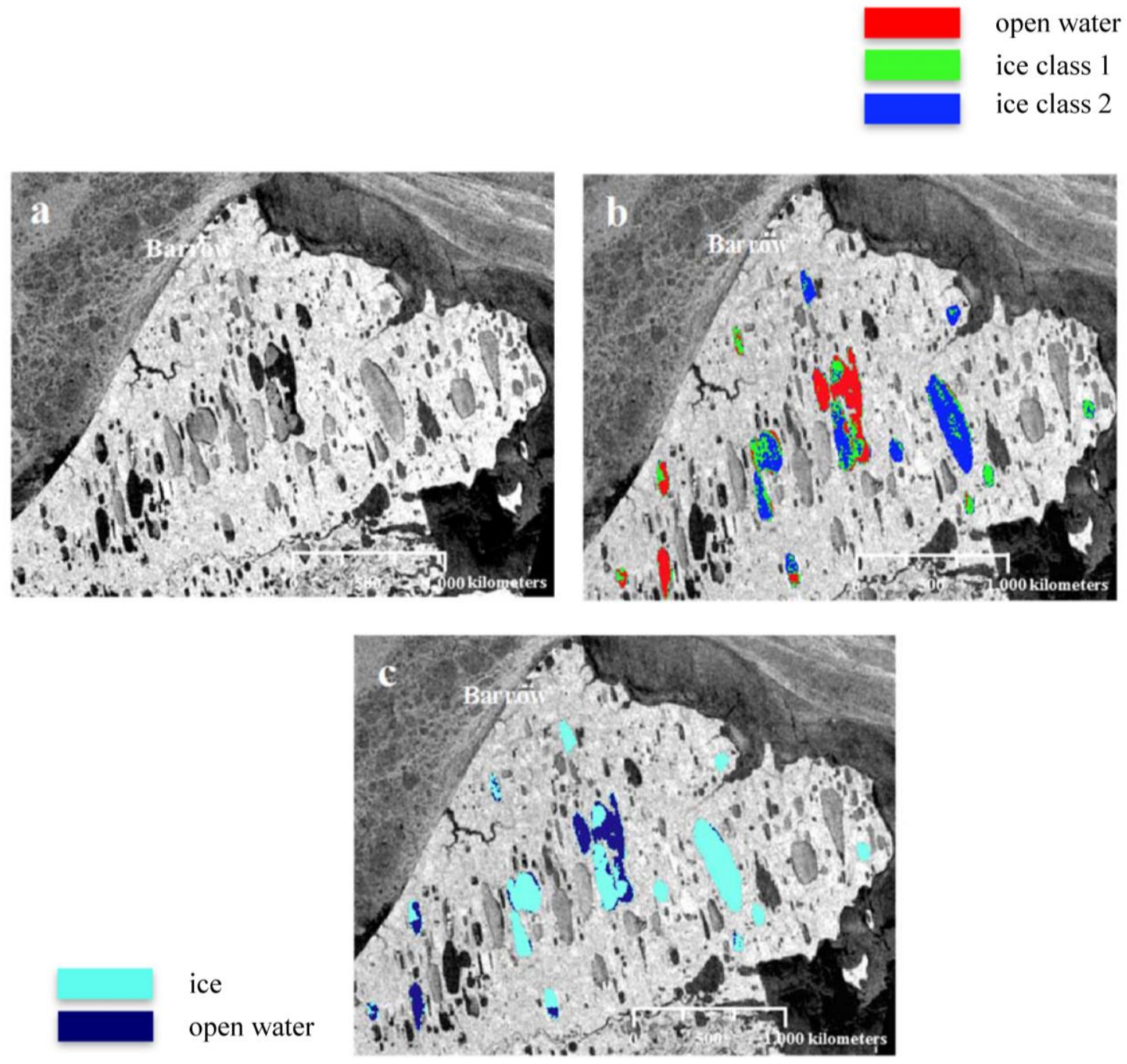

Figure 2. K-means image segmentation process of SAR images: (a) original SAR image; (b) K-means segmentation results (one open-water class and two ice classes) and (c) two-class map (ice in light blue and open water in dark blue).

\subsection{Lake-Ice Modeling}

The one-dimensional Canadian Lake Ice Model (CLIMo) was used to provide some basis of comparison as to the general ice dates that should be expected from SAR observations. CLIMo was previously tested over freshwater Arctic lakes, including those located in the area of this study [3,30-33]. Optimal model simulations were obtained for ice phenology of shallow lakes. Previous studies showed that the model performs very well if driven with data representative of the lakes' climate [31,33] and can provide simulated freeze-up and break-up dates. The model was driven with climate data acquired from the nearby 
meteorological station of Barrow. While the spatial variability within a lake or a region is shown by SAR observations, CLIMo does not capture this variability, as the one-dimensional model provides one ice-on and one WCI date for the one set of input climate data.

Along with energy balance components, on-ice snow depth, and composition of the ice cover (clear ice and snow ice proportions), the model also simulates lake ice thickness and annual complete-freeze-over and WCI dates. Considering the variability of the snow depth over lakes in coastal regions, the model was run with a snow cover depth scenario of 53\%. This value represents the ratio (expressed as a percentage) of snow depth measured on lakes to that measured on land in the study area. The ratio was calculated based on in situ snow depth measurements available from previous studies [3,16,34]. Making reference to existing field measurements, the model was driven with a set dry snow density of $335 \mathrm{~kg} \cdot \mathrm{m}^{-3}$. Modelled freeze-up, initial ice-melt and break-up dates were compared to FO, MO and WCI dates as derived from SAR observations.

\subsection{Meteorological Data}

Climate records from the Barrow, AK, meteorological station, obtained from NOAA's National Climatic Data Centre (NCDC), were used to force CLIMo and to assess the effect of temperature and snow on SARdetected ice phenology. Mean daily screen-height air temperature, relative humidity, wind speed, cloud cover fraction, and snow depth were used to force CLIMo in order to simulate ice-on and ice-off dates for lakes in the region of study.

\subsection{MODIS Lake/Ice Surface Temperature}

Moderate Resolution Imaging Spectroradiometer (MODIS) land/lake surface temperature data was acquired from 2006 to 2011. MODIS pixels were identified for each of the 14 ROIs (lakes) shown in Figure 1 and listed in Table 1, and used in the analysis of $\sigma^{\circ}$ values in relation to lake surface "skin" temperature. Selection of MODIS pixels was carefully performed in order to avoid land contamination and included MODIS pixels closer to the lake areas of interest. The pixels were selected based on two criteria: first, the proximity to the selected SAR ROIs, and second, each MODIS pixel had to be $95 \%$ over lake.

In this study, the MODIS UW-L3 Lake Surface Water Temperature (LSWT) product was used [35,36]. The product is generated from Aqua and Terra MYD/MOD 11-L2 data, at a spatial resolution of $1 \mathrm{~km}$. A new algorithm was developed to create products at various temporal resolutions from the combination of MODIS data from the Aqua and Terra satellites, which were not available otherwise (see [37,38] for details). The Aqua and Terra satellite platforms follow the same orbit within three hours of each other. However, at higher latitudes, it is possible to monitor the same location from both sensors within an hour, considering different viewing angles. In such case, it is feasible to combine observations from both sensors in each pixel during an hour. The MODIS UW-L3 LSWT/LIST product has been evaluated against in situ temperature measurements over Finnish lakes [36,39] as well as one-dimensional lake models over two large Canadian lakes [35].

From 2006 to 2011, MODIS temperature data highly correlated with that recorded at the Barrow meteorological station $(r=0.94-0.99)$. However, the satellite "skin" temperature within a MODIS pixel over a lake located $9.3 \mathrm{~km}$ away from Barrow was generally lower than the 2-m air temperature recorded locally by $1.86^{\circ} \mathrm{C}$ to $2.95^{\circ} \mathrm{C}$ during all years of analysis. Differences between the two temperatures are 
expected, as they do not represent the same measurement (2-m height vs. "skin" temperature). A comparison of near-surface air temperature from the Barrow meteorological station and from MODIS is shown in Figure 3.

(a)

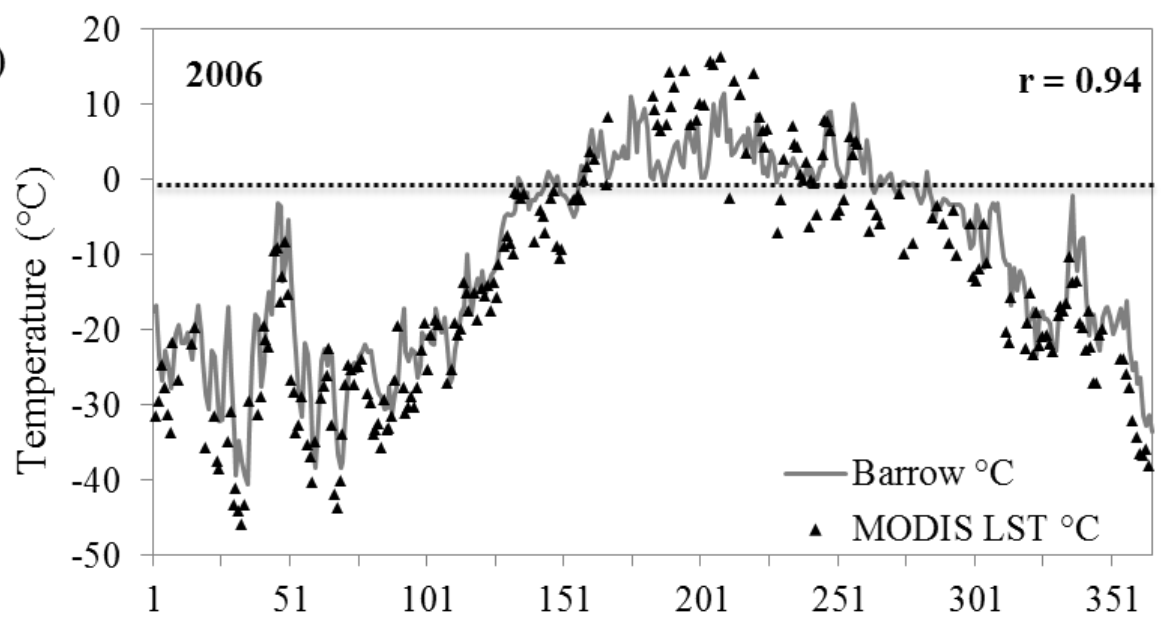

Day of the Year (DOY)

(b)

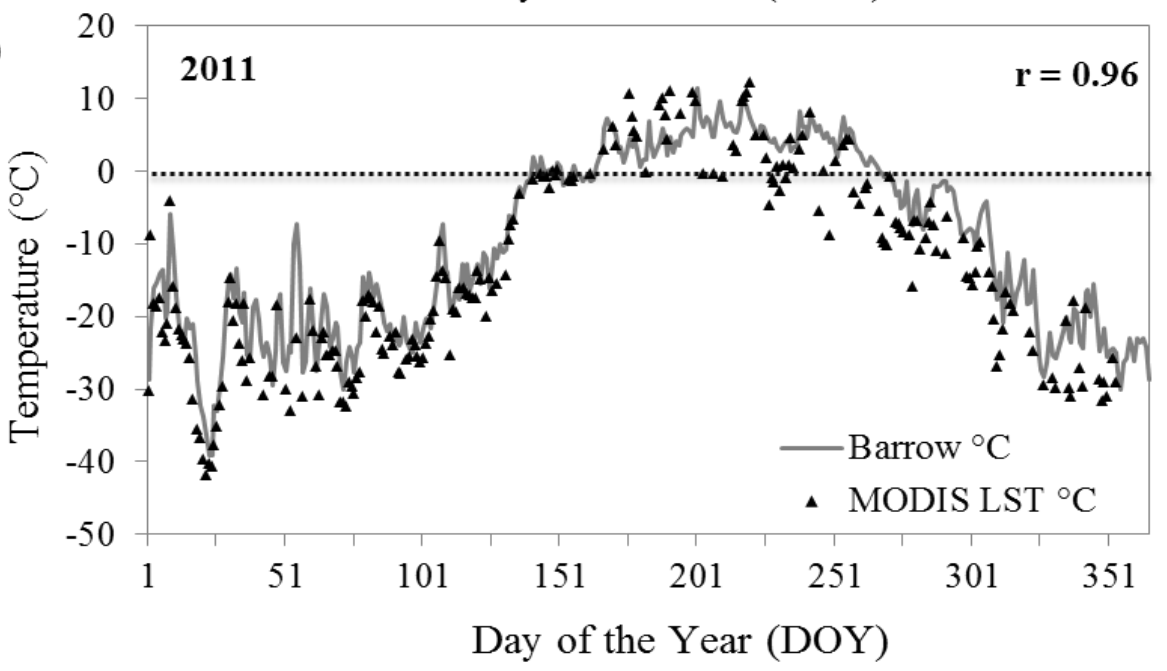

Figure 3. MODIS LSWT/LIST compared to the surface air temperature registered at Barrow in (a) 2006 and (b) 2011. The Pearson correlation (r) between the observations is also shown.

\section{Results}

Temporal analysis of radar returns indicates a strong $\sigma^{\circ}$ relation with temperature, with lower air temperatures generally leading to an increase in $\sigma^{\circ}$ and higher air temperatures resulting in a decrease of $\sigma^{\circ}$ values. ASAR and RADARSAT-2 acquisitions were available for an overlapping period (2009-2011). During this period with more frequent observations, the detection accuracy of ice phenology events increased. However, several limitations have also been identified and they are related to the wide range of incidence angles at which images were acquired, to the different polarization modes of ASAR, and possibly to the alternating ascending and descending orbits for both ASAR and RADARSAT-2. 


\subsection{Freeze-Up}

Initial ice formation for shallow Alaskan lakes was monitored from 2005 to 2011 and FO dates were compared to model outputs (Table 2). The mean ice onset date for this period as derived from SAR observations is 28 September (DOY271), closely aligning with the date indicated by model simulations, 1 October (DOY274). Temporal analysis of $\sigma^{\circ}$ indicates that the latest FO occurred in 2008 (7 October, DOY280) and the earliest in 2005 (15 September, DOY258). Results show that with the exception of 2010 , ice onset of each year occurred later than the previous year. The $\sigma^{\circ}$ values at the beginning of ice formation exhibit returns ranging from $-15.9 \mathrm{~dB}$ to $-4.8 \mathrm{~dB}$ for ASAR and from $-17.4 \mathrm{~dB}$ to $-11.7 \mathrm{~dB}$ for RADARSAT-2.

Table 2. Timing of lake-ice freeze onset dates between 2005 and 2011 derived from SAR backscatter and model simulations, shown as day of the year. The missing value indicates sparse or missing SAR observations. The range of freeze onset dates for the 14 lakes is shown in parentheses. The number of days difference between SAR observations and CLIMo simulations is also shown as a range.

\begin{tabular}{cccc}
\hline Year & SAR & CLIMo & Difference Range SAR/CLIMo (\# of Days) \\
\hline 2005 & $258(255-261)$ & 270 & $9-15$ \\
2006 & - & 279 & - \\
2007 & $266(263-275)$ & 276 & $1-13$ \\
2008 & $280(279-283)$ & 276 & $3-7$ \\
2009 & $276(271-280)$ & 273 & $2-7$ \\
2010 & $271(265-275)$ & 273 & $2-8$ \\
2011 & $276(274-280)$ & 274 & $0-6$ \\
Mean FO 2005-2011 & $271(255-283)$ & 274 & $0-15$ \\
\hline
\end{tabular}

\subsection{Break-Up}

Timing of MO and WCI dates for coastal shallow lakes on the NSA is reported from 2006 to 2011. The scarcity of the ASAR acquisitions throughout the 2008 break-up season did not allow accurate detection of ice events and thus these observations were not included in the analysis.

Analysis of SAR $\sigma^{\circ}$ indicates that the mean MO date for shallow lakes on the NSA from 2006 to 2011 is 23 May (DOY143). SAR observations show a relatively high variability of MO dates during the six years of monitoring, with the latest MO occurring in the spring of 2008, on 4 June (DOY155) and the earliest in 2011, on 13 May (DOY133). Results show that SAR-derived mean MO dates are similar to CLIMo simulations (Table 3), model outputs indicating 16 May (DOY136) as the mean MO date. The higher discrepancy between SAR observations and model output in 2008 is explained by the lack of ASAR observations at the beginning of ice decay, between 15 May (DOY136) and 3 June (DOY155). The differences between SAR-observed and simulated MO dates are partially explained by the gap of 2-5 days (2009-2011) and of 2-19 days (2005-2008) between observations. At the beginning of the break-up period, $\sigma^{\circ}$ ranged from $-20.44 \mathrm{~dB}$ to $-15.66 \mathrm{~dB}$ for ASAR and from $-22.87 \mathrm{~dB}$ to $-16.11 \mathrm{~dB}$ for RADARSAT-2.

From 2006 to 2011, the mean WCI (ice-off) date for lakes on the Alaskan North Slope as indicated by SAR observations is 10 July (DOY191). Results are indicative of a relatively small variability (1-8 days) in the WCI dates during the six-year period, with the latest WCI date occurring on 14 July 2010 (DOY195) 
and the earliest on 6 July 2009 (DOY187) (Table 4). The sparse SAR acquisitions during the end of the 2008 break-up of period did not allow accurate detection of the WCI date. CLIMo mean WCI dates from 2006-2011 are similar with those observed with SAR (10 July, DOY191) during the same period (9 July, DOY190). These results are similar to previous MODIS-Terra observations (with a spatial resolution ranging from 250-1000 m) of WCI timing for larger lakes on the Arctic Coastal Plain from 2007-2012, identifying 6 July (DOY187) as the mean WCI date [15]. More specifically, the same study [15] identifies 4 July (DOY185) as the mean WCI date in 2007 and 2008, 2 July (DOY183) in 2009, 13 July (DOY194) in 2010 and 6 July (DOY187) in 2011. The coarser MODIS spatial resolution may explain the generally earlier WCI dates detected by this sensor compared to the WCI dates observed with the higher-resolution SAR.

Table 3. Timing of lake-ice melt onset between 2006 and 2011, derived from SAR backscatter and model simulations. Dates are shown as day of the year. The range of melt onset dates for the 14 lakes is shown in parentheses. The number of days difference between SAR observations and CLIMo simulations is also shown as a range.

\begin{tabular}{cccc}
\hline Year & SAR & CLIMo & Difference Range SAR/CLIMo (\# of Days) \\
\hline 2006 & $141(131-151)$ & 134 & $3-17$ \\
2007 & $141(136-145)$ & 144 & $1-8$ \\
2008 & $156(155-158)$ & 138 & $17-20$ \\
2009 & $143(137-149)$ & 132 & $5-17$ \\
2010 & $147(144-150)$ & 145 & $1-5$ \\
2011 & $133(128-145)$ & 139 & $6-9$ \\
Mean MO 2006-2011 & $143(128-158)$ & 136 & $1-20$ \\
\hline
\end{tabular}

Table 4. Lake water-clear-of-ice timing between 2006 and 2011, derived from SAR backscatter and model simulations. Dates are shown as day of the year. The missing value indicates sparse or missing SAR observations. The range of water-clear-of-ice dates for the 14 lakes is shown in parentheses. The number of days difference between SAR observations and CLIMo simulations is also shown as a range.

\begin{tabular}{cccc}
\hline Year & SAR & CLIMo & Difference Range SAR/CLIMo (\# of Days) \\
\hline 2006 & $194(189-198)$ & 193 & $4-5$ \\
2007 & $190(189-190)$ & 189 & $0-1$ \\
2008 & - & 186 & - \\
2009 & $187(178-190)$ & 186 & $4-8$ \\
2010 & $195(192-198)$ & 194 & $2-4$ \\
2011 & $198(196-201)$ & 192 & $4-9$ \\
Mean WCI 2006-2011 & $191(178-201)$ & 190 & $0-9$ \\
\hline
\end{tabular}

\section{Discussion}

\subsection{Timing of Key Lake-Ice Events}

Timing of initial ice formation (FO), beginning (MO) and end of ice break-up (WCI) for lakes on the NSA from 2005 to 2011 was determined for 14 selected ROIs using the SAR $\sigma^{\circ}$. Temporal evolution of 
$\sigma^{\circ}$ was analyzed in relation to MODIS LSWT/LIST and/or weather station temperature (Figure 4) and snow depth.

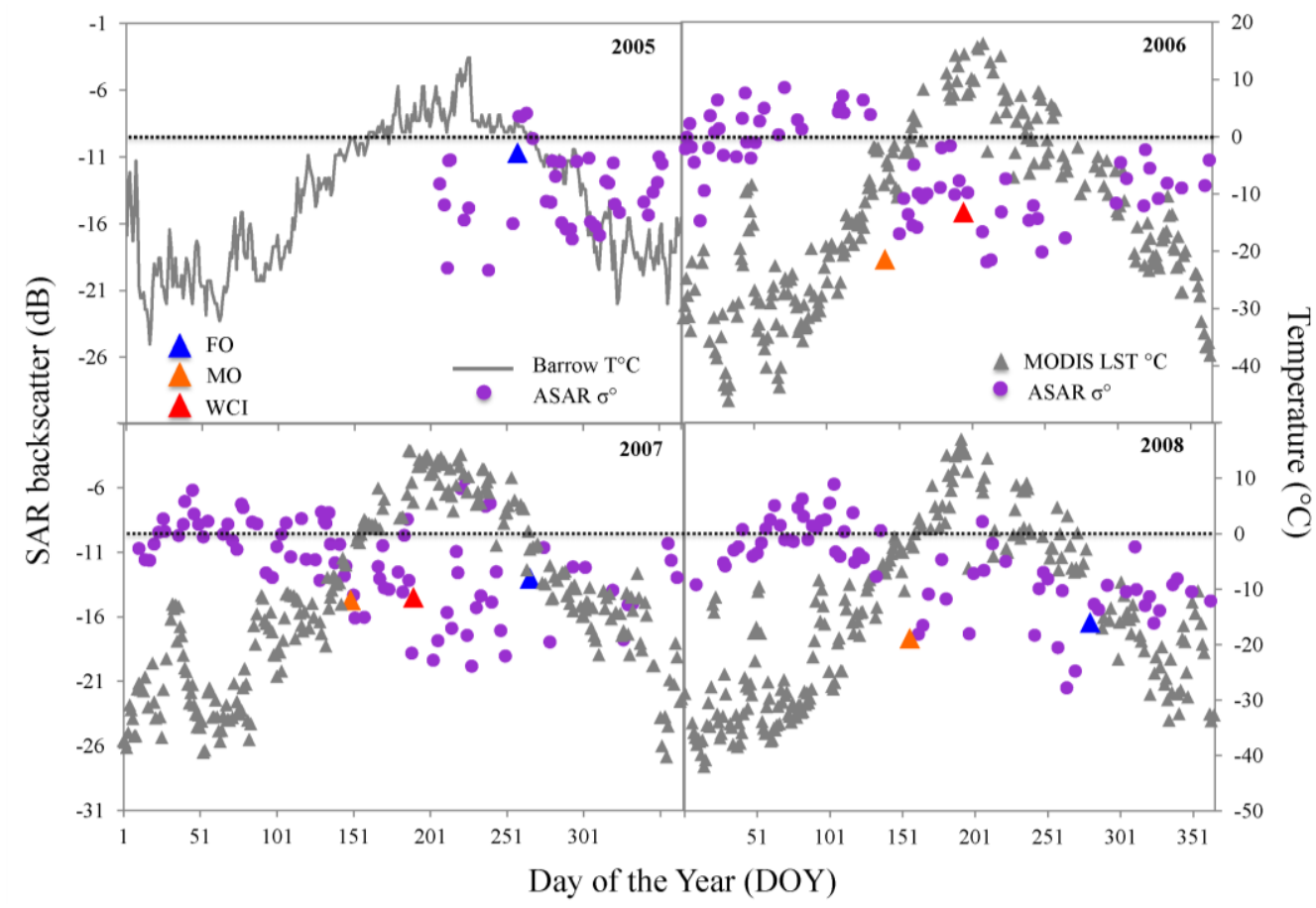

(a)

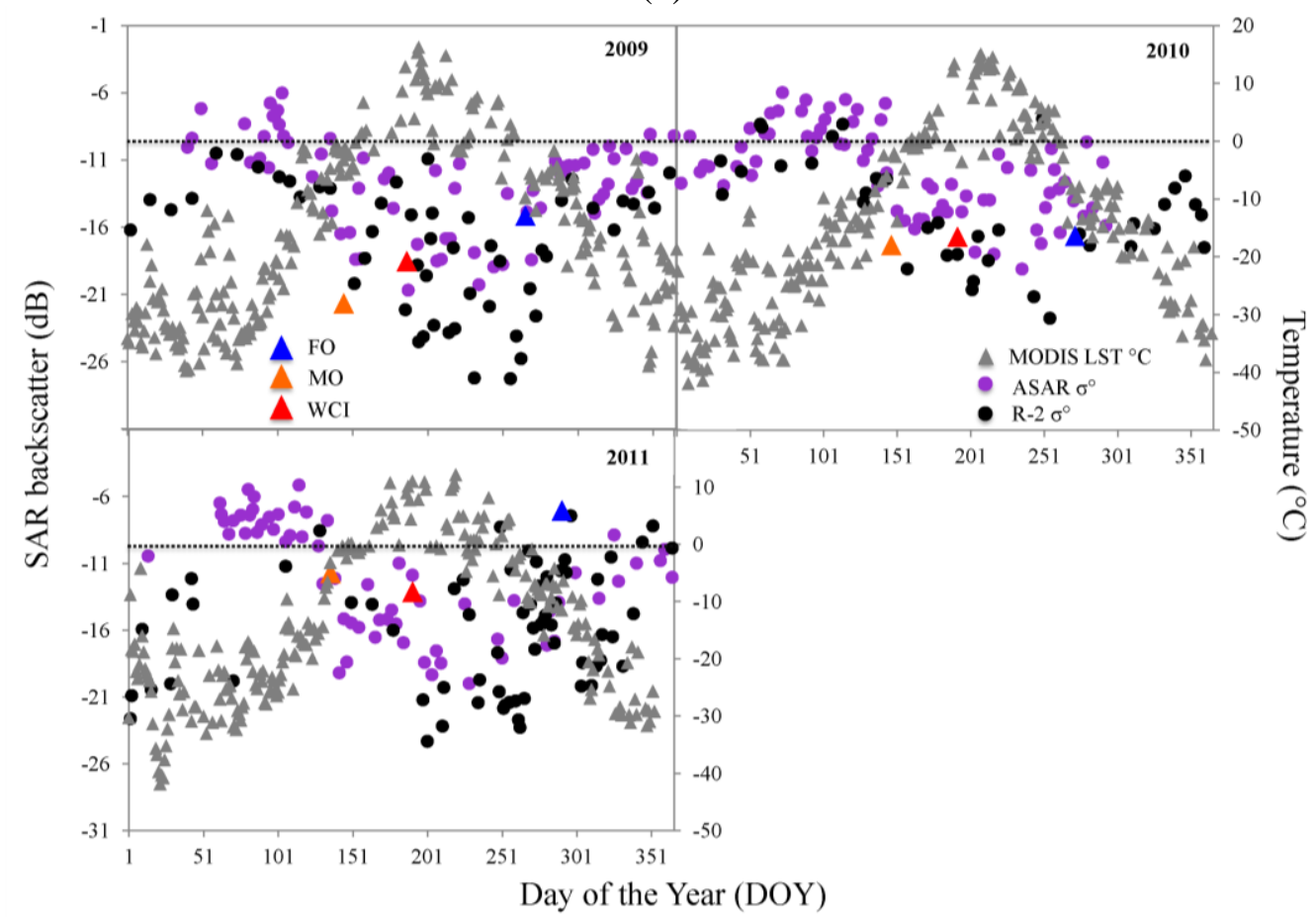

(b)

Figure 4. Temporal evolution of SAR backscatter over a shallow lake near Barrow, Alaska: (a) ASAR (2005-2008); and (b) ASAR and RADARSAT-2 (2009-2011). The solid grey line represents recorded air temperature at the meteorological station and the grey triangles represent the observed MODIS LST. SAR-detected freeze onset (blue triangles), melt onset (orange triangles) and water-clear-of-ice (red triangles) dates are also shown. No waterclear-of-ice dates are shown if SAR acquisitions were missing or sparse. 


\subsubsection{Freeze Onset}

As a result of increased sampling frequency (combined ASAR and RADARSAT-2 acquisitions) between 2009-2011, accuracy of FO detection in relation to model simulations increased, fact reflected by the similar mean FO dates observed with SAR, with 1 October (DOY274) as the mean FO date, and those simulated with CLIMo for the same period, with the mean FO date as 30 September (DOY273). Greater differences in timing of mean FO dates were noticed between SAR observations (25 September, DOY268) and model simulations (1 October, DOY274) from 2005 to 2008, when only ASAR data was available. During years when differences between SAR observations and model outputs are greater (e.g., 2005 and 2006), uncertainties associated with high $\sigma^{\circ}$ from wind-roughened open water provide a possible explanation for these discrepancies. The differences between observations and simulations can also be explained by the fact that CLIMo was forced with data from the weather station. As a result, the model outputs would indicate later FO (and earlier WCI) dates. These discrepancies can also be explained by the fact that the model provides only one FO date for all lakes in the Barrow region whereas FO dates observed with SAR apply to each individual lake and display a range (as shown in Table 2). The SAR-observed FO dates and are then reported as a mean date.

Ice formation is a function of decreasing air temperatures and lake morphometry, as lakes store different amounts of heat accumulated in the warmer months prior to the event, depending on depth, area and volume [40]. Once lake water achieves its maximum density at $3.98^{\circ} \mathrm{C}$ consequent to heat loss at the air-water interface, deeper warmer waters replace the denser surface ones and additional cooling continues until a solid ice cover develops [40]. Given that most lakes in the study area are shallow, the effect of heat storage and circulation is reduced [41].

Usually, ice starts forming once air temperatures fall below $0^{\circ} \mathrm{C}$. Depending on lake depth and volume, and also on wind events that may occasionally break the thin ice cover, for shallow lakes it may take several days from the initial drop in air temperature until a more solid ice cover forms. For instance, in 2007 negative air temperatures were registered on 21 September (DOY264) and mean FO date was estimated to be on 23 September (DOY266). Conversely, in 2009 consistent negative air temperatures were recorded after 20 September (DOY263) and mean FO was only detected on 3 October (DOY276). Similarly, in 2011, FO was observed on 3 October, following 12 days of below-freezing air temperatures.

The two extreme FO dates shown by the temporal analysis of $\sigma^{\circ}$-late in 2011 (11 October) and early in 2005 (15 September) — could be explained by the differences in air temperatures prior to ice onset (Figure 5). Mean September air temperatures $\left(2.76^{\circ} \mathrm{C}\right)$ have possibly contributed to the late FO of 2011 . The early ice onset in 2005 was possibly related to the lower mean September air temperature $\left(1.08^{\circ} \mathrm{C}\right)$ when compared to the mean air temperature of the same month in 2011.

At high wind speeds, radar returns with values close to $0 \mathrm{~dB}$ could be distinguished from the newly formed ice. These high $\sigma^{\circ}$ values were considered to be low-quality pixels and were not included in the analysis but were useful as they were indicative of the presence of new ice. 


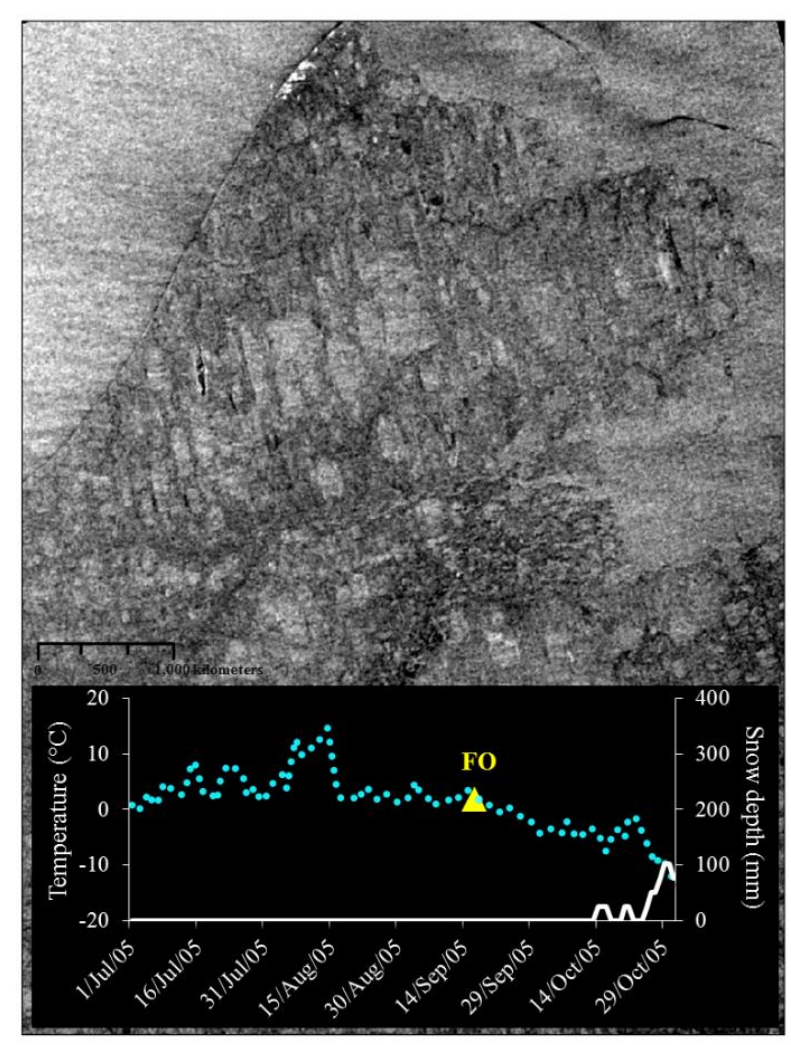

(a)

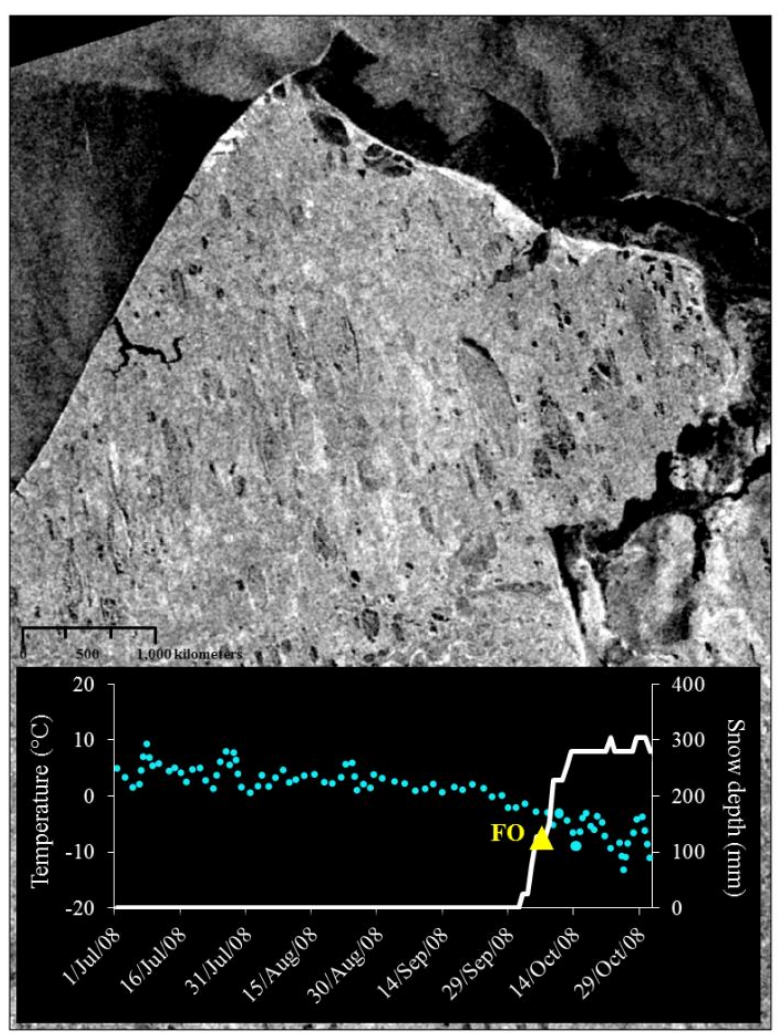

(b)

Figure 5. SAR images acquired at the time of freeze onset-(a) ASAR, 18 September 2005; (b) ASAR, 9 October 2008 —of lakes on the North Slope of Alaska. The bottom graphs show climate conditions - air temperature (blue dots) and snow depth on ice from CLIMo (white line) prior and at the time of freeze onset. SAR-detected freeze onset dates are also indicated (yellow triangles).

\subsubsection{Melt Onset}

At the beginning of the break-up period, snow controls the $\sigma^{\circ}$, regardless of the ice type, as wet snow prohibits penetration of the radar signal below this layer [22] and thus resulting in low radar returns, consequence of the radar signal reflecting off the wet layer (specular reflection). Depending on the ice type, the timing and length of ice decay is affected, with snow ice delaying the ice decay. If snow on ice or snow ice is present, its higher albedo delays break-up [41]. Once snow has melted, the internal structure of ice crystals is disintegrated by solar radiation and mechanical break-up [42], and the albedo of the lake surface gradually decreases as more water is exposed to radiative warming, and melt accelerates with further heating. This is also the case for MO observed throughout the 2006-2011 period. More specifically, in the spring of 2008, climate records from Barrow indicate that following the transition toward above-freezing air temperatures, snow fully melted on 2 June and the MO of ice occurred two days later. Similarly, following higher air temperatures in late May 2011, MO occurred a few days prior to complete snow melt (Figure 6).

$\mathrm{MO}$ is associated with positive air temperatures values but internal melt of the ice crystals may begin even at air temperatures slightly below $0^{\circ} \mathrm{C}$. Air temperatures over $0^{\circ} \mathrm{C}$ were recorded, starting with 6 June (DOY157) in 2006 and 3 June (DOY154) in 2007. In 2008 and 2009, MO occurred 5-6 days after 
above-freezing temperatures were recorded. In 2008, mean MO was observed on 5 June (DOY 156) and 23 May (DOY143), respectively, while LSWT/LIST above $0^{\circ} \mathrm{C}$ were recorded starting with 30 May (DOY150) and 18 May (DOY138). In 2010 and 2011, MO preceded above-freezing air temperatures by four and nine days, respectively. Nevertheless, the evolution of $\sigma^{\circ}$ closely follows that of air temperature and when available that of LSWT/LIST, ice events occurring within 3-16 days prior or subsequent to changes in air temperatures/LSWT/LIST.

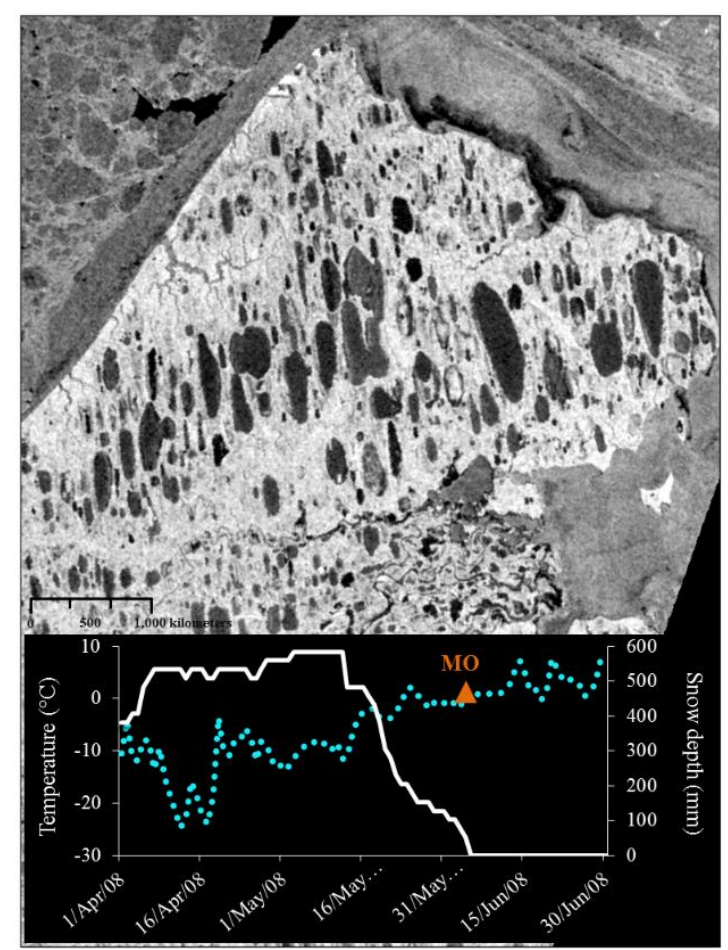

(a)

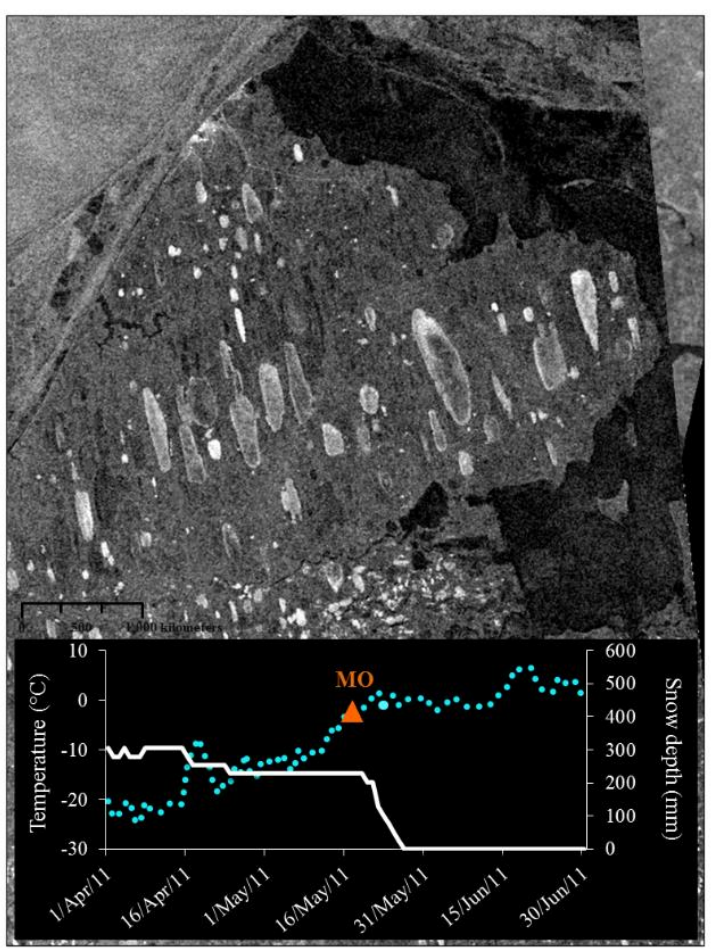

(b)

Figure 6. SAR images acquired at the time of melt onset-(a) ASAR, 10 June 2008 and (b) RADARSAT-2, 16 May 2011 —of lakes on the North Slope of Alaska. The bottom graphs show climate conditions - air temperature (blue dots) and snow depth on ice from CLIMo (white line) prior and at the time of melt onset. SAR-detected melt onset dates are also indicated (orange triangles). RADARSAT-2 Data and Products MacDonald ${ }^{\odot}$, Dettwiler and Associates Ltd., 2011-All Rights Reserved. RADARSAT is an official trademark of the Canadian Space Agency.

\subsubsection{Water-Clear-of-Ice}

Radar signal from the ice oscillates during the break-up period. Consequent to warmer air temperatures, the low radar returns at the beginning of spring signal the onset of ice melt. Following observations of low $\sigma^{\circ}$, higher returns are noticed, indicating subsequent re-freeze events, mainly due to ascending (morning) and descending (evening) acquisitions, and/or that water has drained from the ice surface. Excluding the images affected by wind effect, indicated by high radar returns, these values gradually decrease closer to the WCI date, when air temperatures have been consistently positive. The open water season is indicated by consistent significant low $\sigma^{\circ}$ values $(-24.88 \mathrm{~dB}$ to -19.62 for ASAR and $-28.54 \mathrm{~dB}$ to -20.47 for RADARSAT-2). 
Snow has been demonstrated to be a significant driver of lake-ice growth as variations in snow duration and depth have direct consequences on a lake's thermal regime and winter energy balance [34], and impact the timing of WCI. A thinner (about half of the terrestrial snow [34]) and a denser snowpack provides less insulation, allowing higher rates of heat flow to the atmosphere in spring [34]. Knowledge of snow conditions over lakes is useful in predicting timing the WCI dates, as break-up tends to closely follow those of annual number of snow days [43].

In 2009, the LSWT/LIST 5 days prior to the WCI date ranged from $4.7^{\circ} \mathrm{C}-6^{\circ} \mathrm{C}$; in 2010 , the air temperatures five days prior to the $2010 \mathrm{WCI}$ dates were by $2.9^{\circ} \mathrm{C}-3.3^{\circ} \mathrm{C}$ lower. Additionally, in 2010 snow melt occurred later by nine days. Lower air temperatures and later snow-melt likely explain the later WCI date of 2010 (Figure 7).

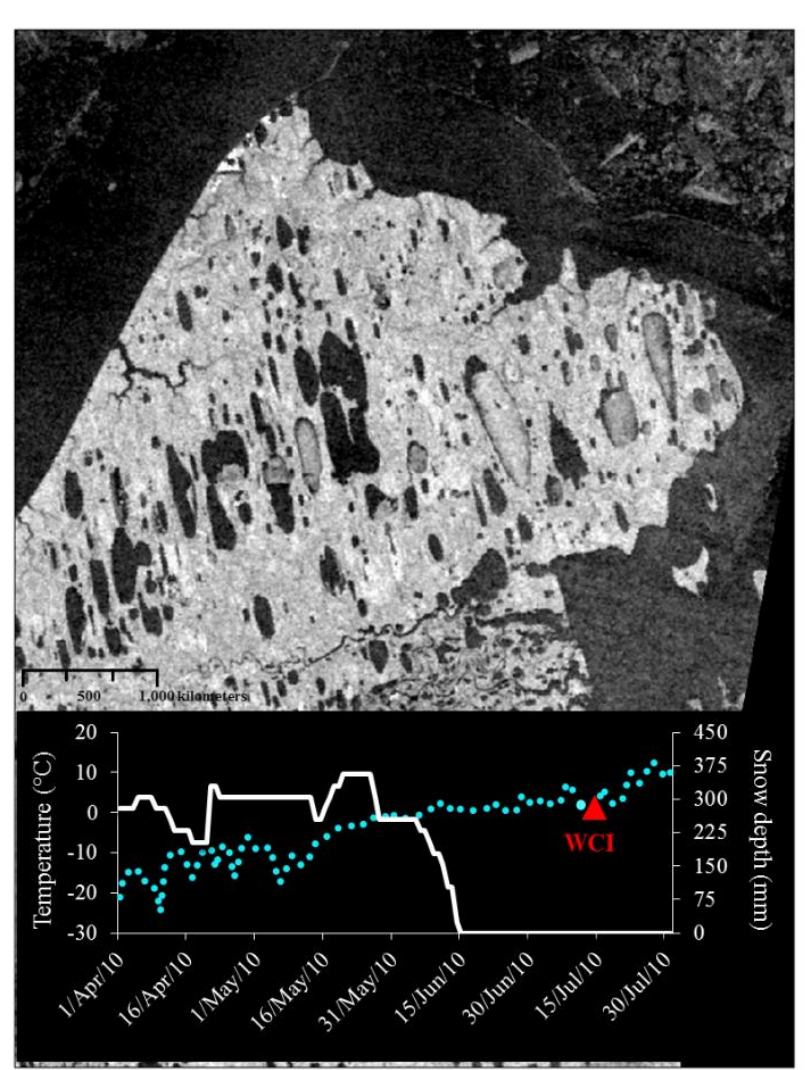

(a)

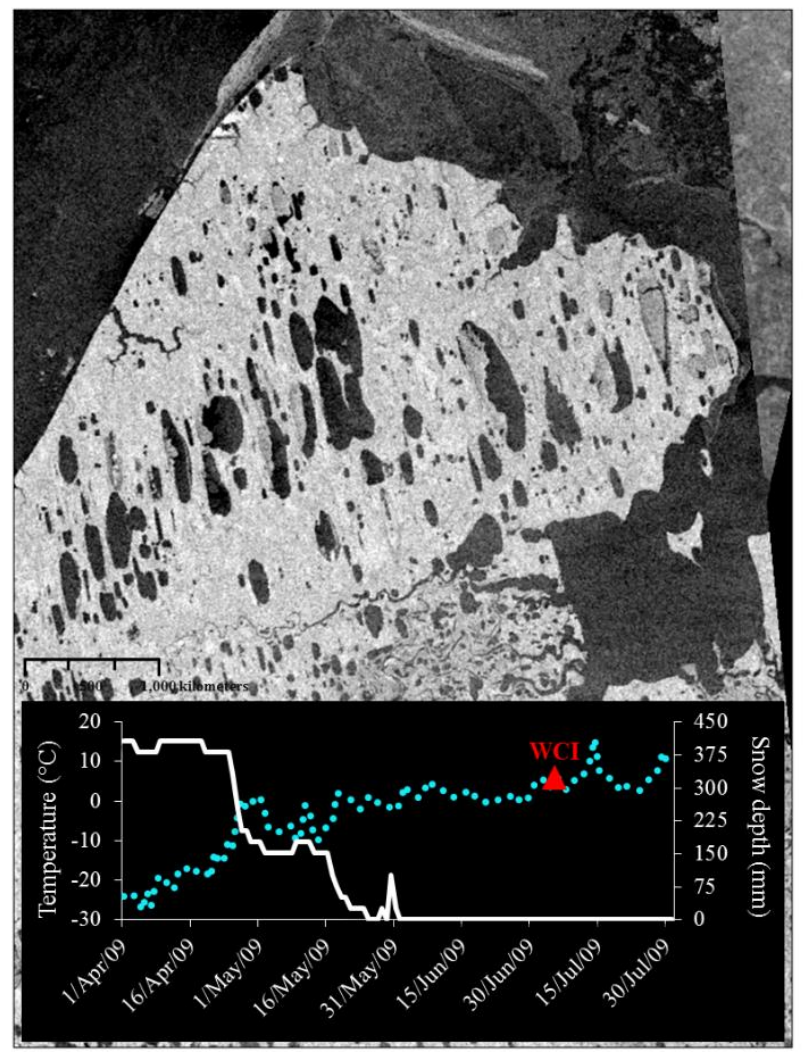

(b)

Figure 7. SAR images acquired at the end of the ice season (WCI)-(a) ASAR, 11 July 2010 and (b) RADARSAT-2, 6 July 2009—of lakes on the North Slope of Alaska. The bottom graphs show climate conditions-air temperature (blue dots) and snow depth on ice from CLIMo (white line) prior and at the time of water-clear-of-ice. SAR-detected waterclear-of-ice dates are also indicated (red triangles). RADARSAT-2 Data and Products MacDonald $^{\odot}$, Dettwiler and Associates Ltd., 2009-All Rights Reserved. RADARSAT is an official trademark of the Canadian Space Agency.

In order to compare the results of the $\sigma^{\circ}$ analysis for WCI timing, segmentation of available SAR images on/close to the WCI date was also performed using the K-means algorithm (Figure 8). Employing the $\sigma^{\circ}$ threshold was necessary to detect important ice events throughout the ice season. The K-means classification 
was solely used for comparison and could not have been used for FO or MO given the limitations associated with discrimination of ice/open water during these ice events. Segmentation results show that no ice was detected on the selected lakes on 14 July 2006, $10 \%$ ice 9 July 2007, 17\% ice on 6 July 2009, 14\% ice on 14 July 2010 and $9 \%$ ice on 10 July 2011. These results are acceptable considering that previous investigations of lake-ice break-up using C-band SAR assigned WCI dates on the dates when the areal fraction of open water first exceeded 90\% [20].

(a)

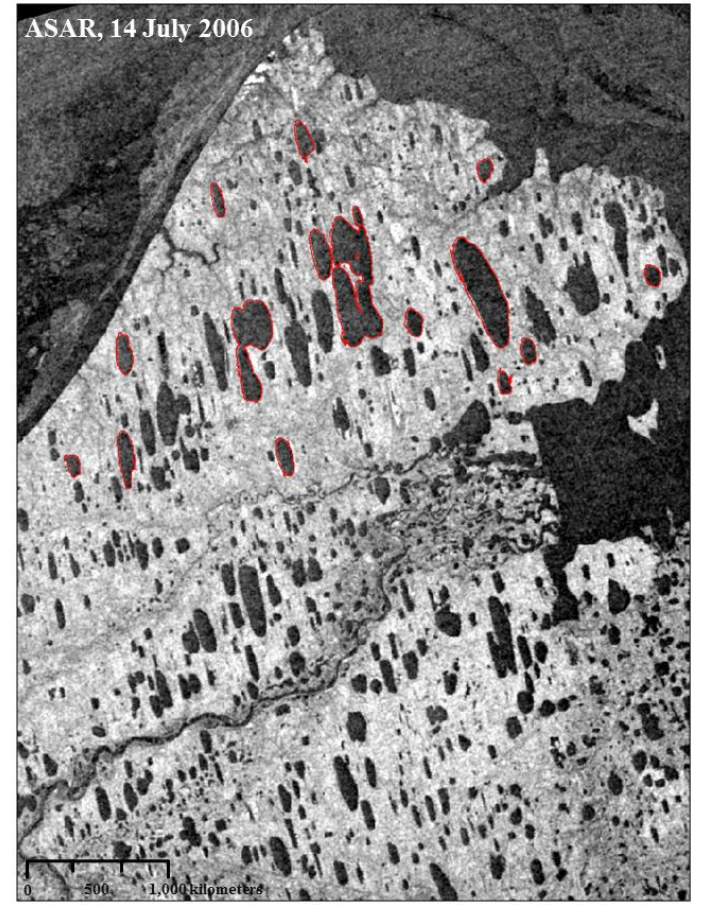

(b)

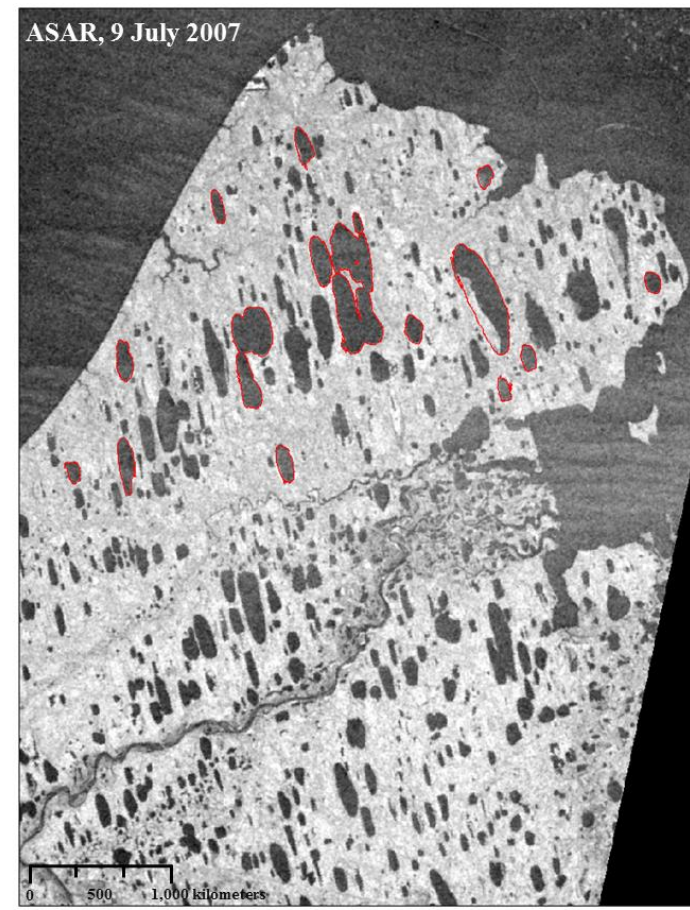

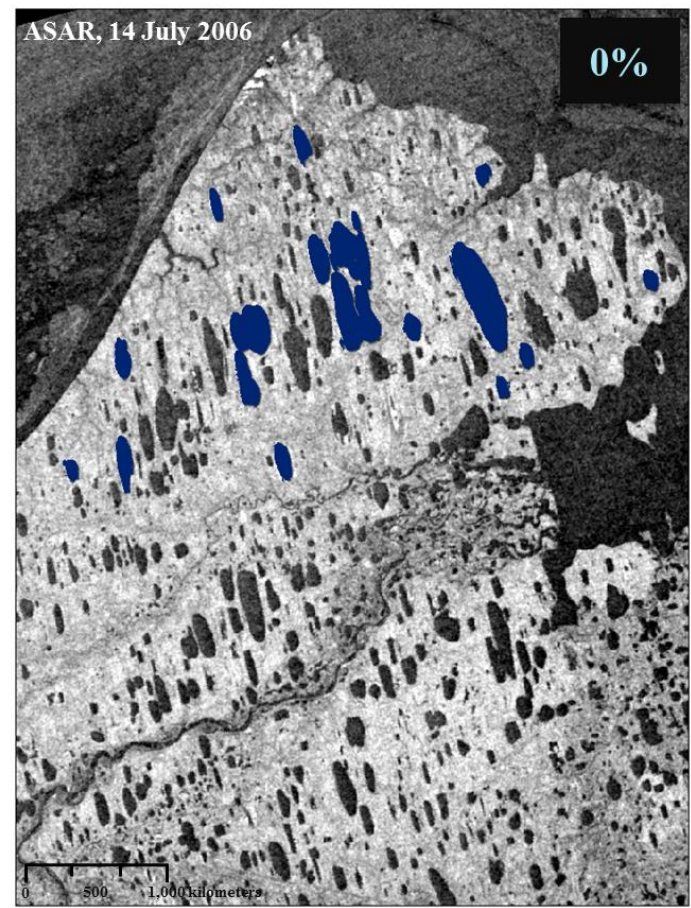

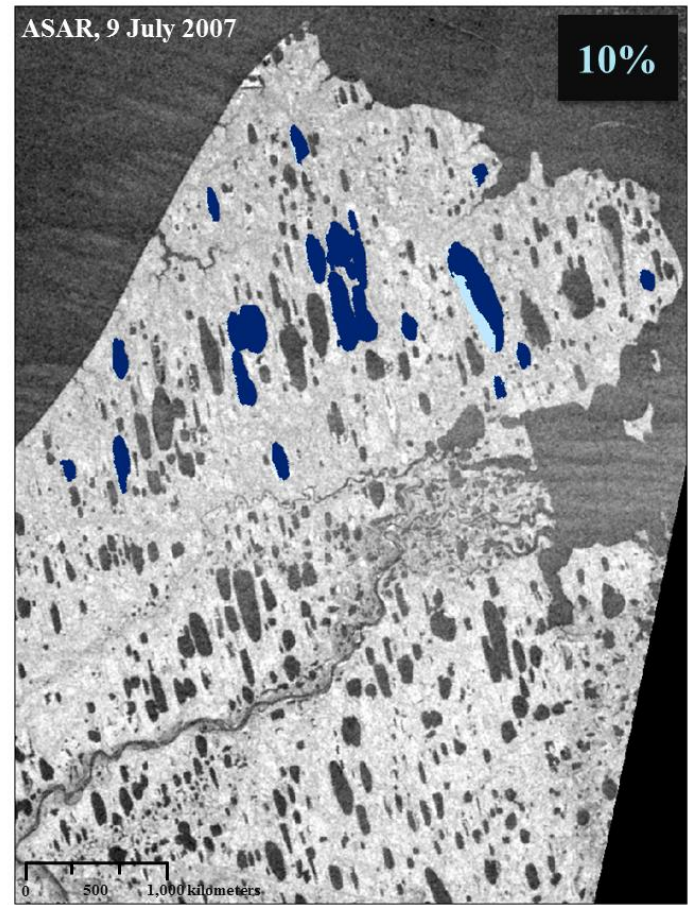

Figure 8. Cont. 
(c)

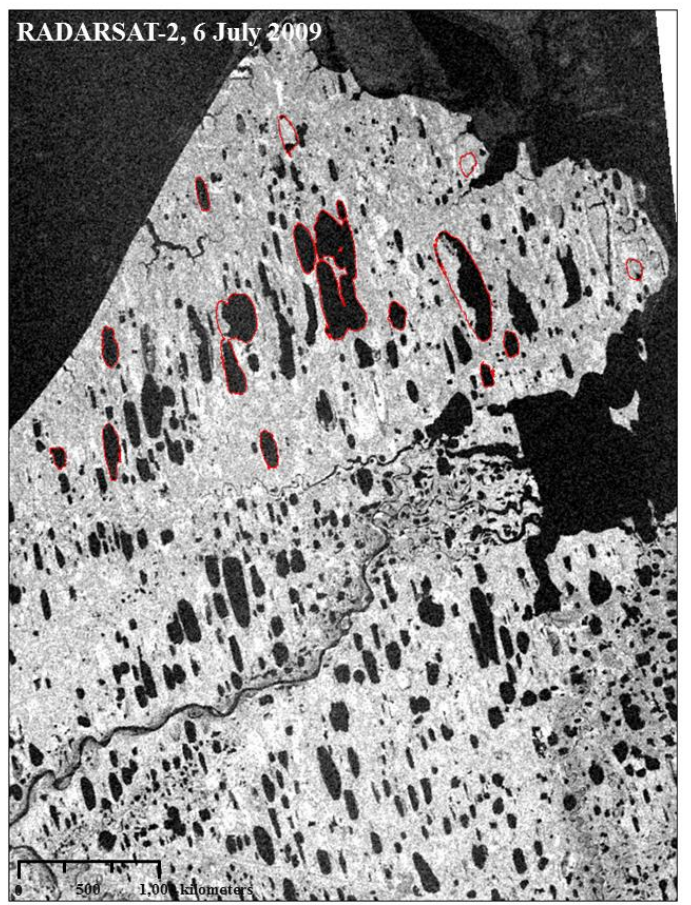

(d)

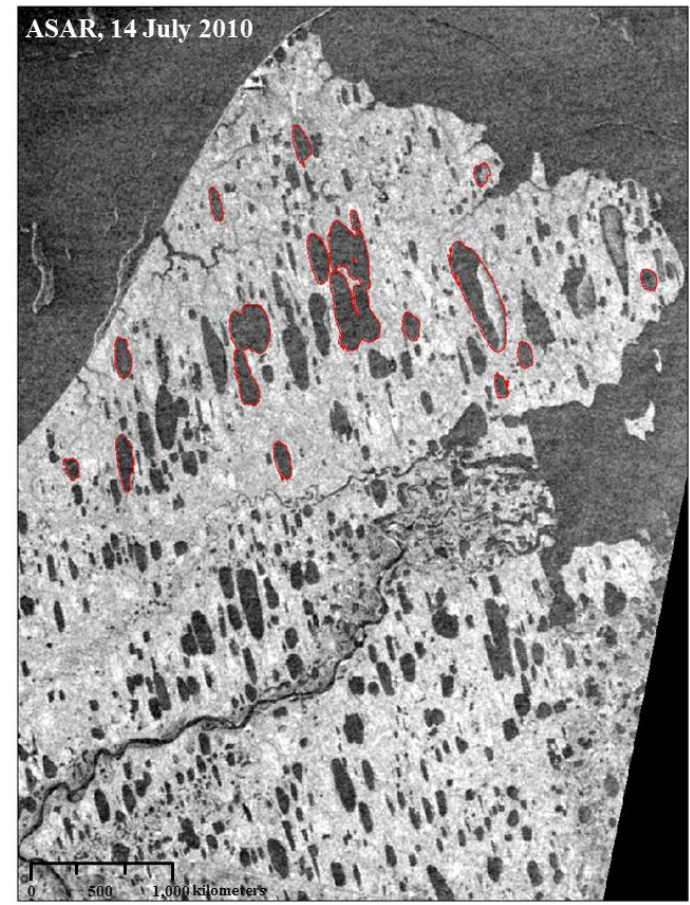

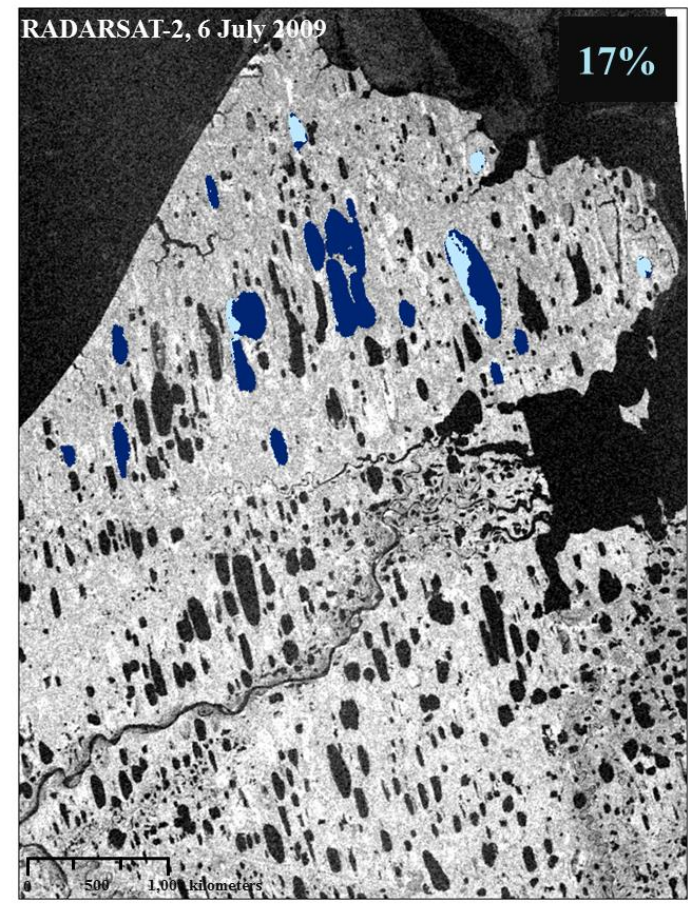

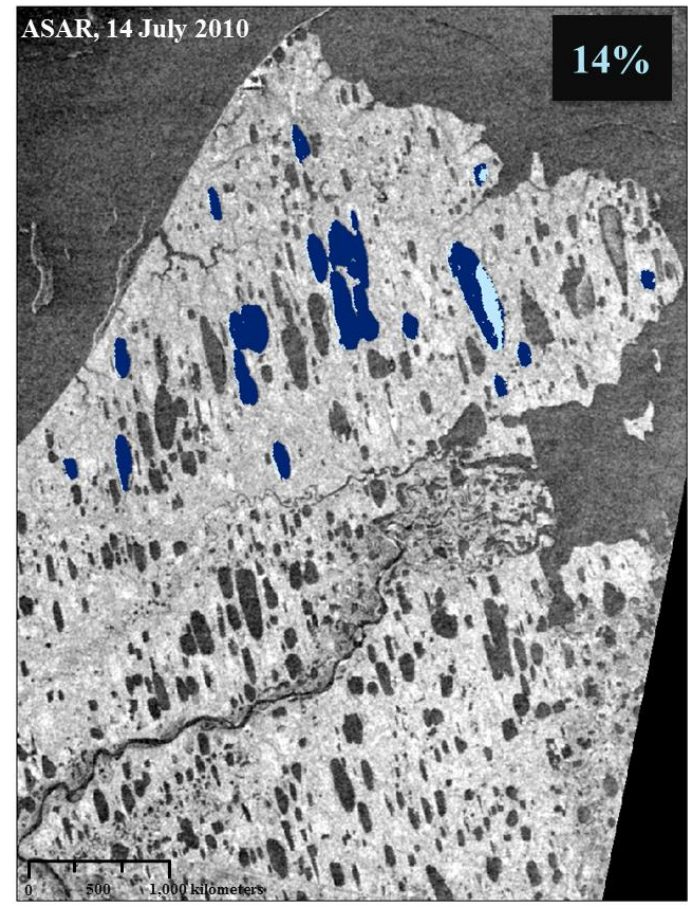

Figure 8. Cont. 

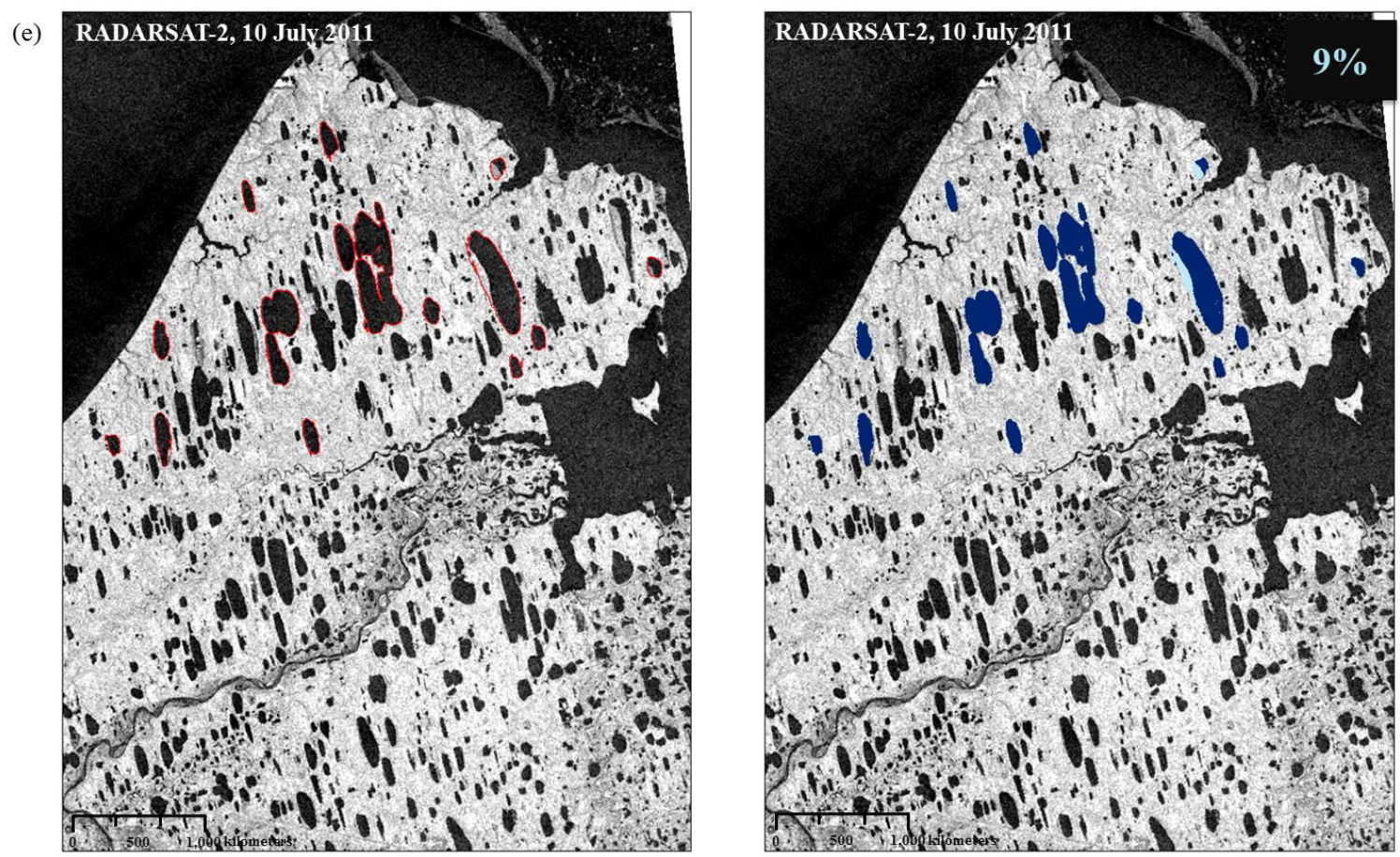

Figure 8. Ice fractions (\%) for 14 lakes near Barrow: (a) 14 July 2006 (DOY195)-ASAR; (b) 9 July 2007 (DOY190)—ASAR; (c) 6 July 2009 (DOY187)—RADARSAT-2; (d) 14 July 2010 (DOY195) —ASAR; and (e) 10 July 2011 (DOY191)—RADARSAT-2. Sparse SAR observations did not allow detection of the water-clear-of-ice date in 2008. The red contours in the original images represent the polygons (ROIs) of the 14 lakes. RADARSAT2 Data and Products MacDonald ${ }^{\odot}$, Dettwiler and Associates Ltd., 2009-All Rights Reserved. RADARSAT is an official trademark of the Canadian Space Agency.

Visual analysis of the segmentation results indicates that Lake Tusikvoak (ROI \# 5, see Table 1 and Figure 1) maintains its ice cover later in the summer, being the lake with the latest WCI date. No other pattern in terms of temporal behavior (i.e. early/late WCI dates during particular years) from 2006 to 2011 was observed for the other lakes.

These results show the potential of frequent C-band $\sigma^{\circ}$ for identification of lake-ice events, such as freeze and melt onset, and WCI dates. The potential of C-band $\sigma^{\circ}$ to discriminate between ice and open water, during both freeze-up and break-up, was shown to be a function of incidence angle and wind; when available, reliable wind data is recommended to be used in analysis [22].

Based on previous findings that suggest that the $\mathrm{HV} \sigma^{\circ}$ does not provide the optimum discrimination between ice and water particularly at the beginning of MO [20], only HH-polarized RADARSAT-2 images were used in the current study. Yet, wind speed prior to the lakes becoming completely ice free affects the HH-polarized imagery, resulting in radar returns similar to those from open water in windy conditions. Consequently, the accuracy of WCI timing could be affected. RADARSAT-2 HH imagery is most useful for WCI detection at incidence angles ranging from $36.6^{\circ}$ to $46.9^{\circ}$, with wind speeds between 2.9 and 7.1 $\mathrm{m} / \mathrm{s}$ [20]. For the purpose of this study, all available HH-polarized SAR images were used. Considering that the frequency of SAR acquisitions ranges from 2 to 5 days, the accuracy in detecting lake-ice events is also dependent on frequency of image acquisition. 


\subsection{Backscatter Sensitivity to Incidence Angle and Polarization}

SAR microwave $\sigma^{\circ}$ is a function of the dielectric properties of the material, local incidence angle and sensor polarization [44]. Both ASAR Wide Swath and RADARSAT-2 ScanSAR Wide provide imagery acquired at a variety of incidence angles (beam modes) and thus increasing the temporal frequency of image acquisition of a stationary target.

Previous investigations of lake ice during spring melt with $\mathrm{C}-\mathrm{HH} \sigma^{\circ}$ measurements report lower $\sigma^{\circ}$ values ( 2 to $5 \mathrm{~dB}$ ) for the same ice cover observed at shallower incidence angles $\left(35^{\circ}-49^{\circ}\right)$ than those at steeper incidence angles $\left(20^{\circ}-35^{\circ}\right)[28,45]$. Similarly, the lake surface $\sigma^{\circ}$ exhibited a decreasing trend with incidence angle, with a sharper decrease for RADARSAT-2 (Figures 9 and 10).

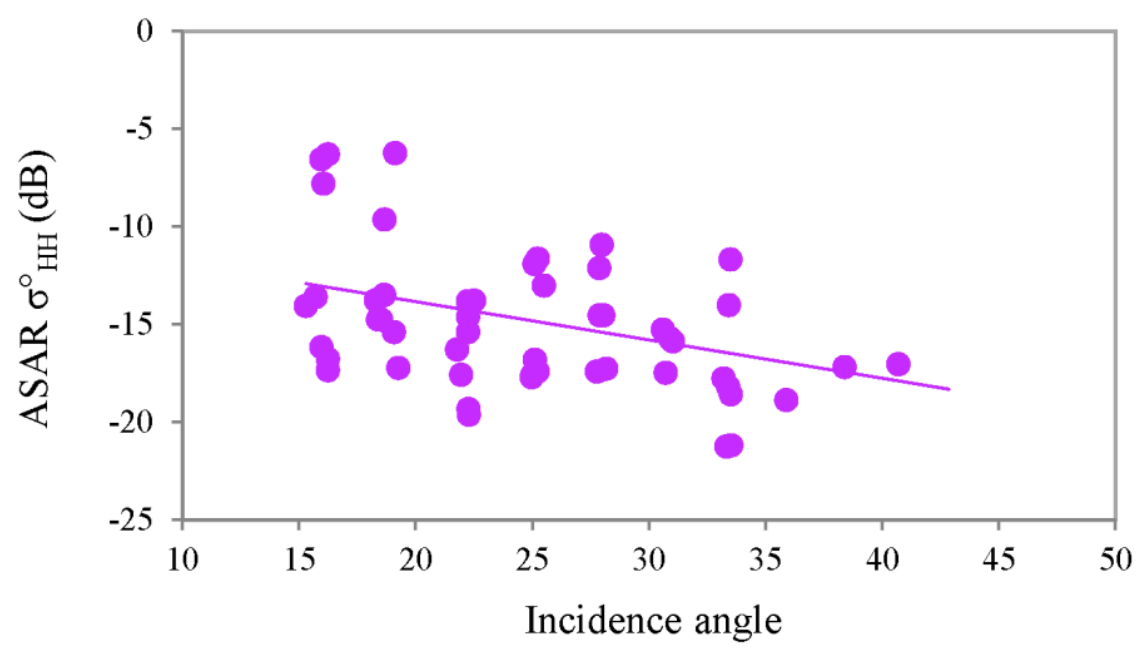

Figure 9. Mean ASAR HH $\sigma^{\circ}$ for selected pixels of a lake that freezes to the bed in late winter. The solid purple line represents a best fit (linear regression) for the available samples.

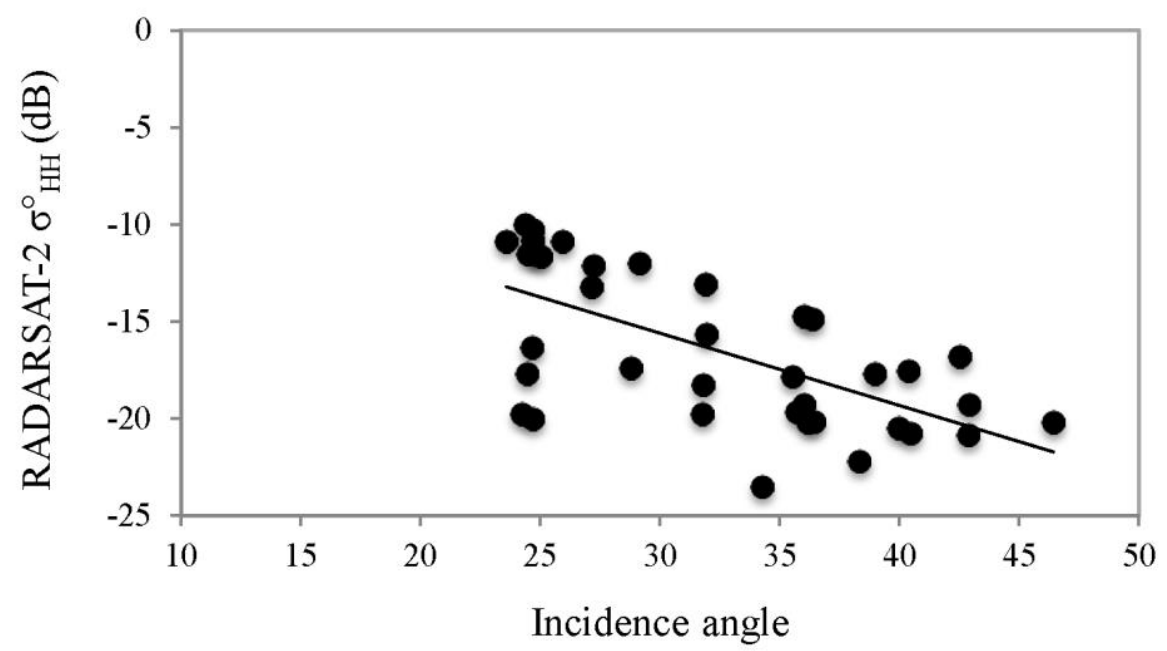

Figure 10. Mean RADARSAT-2 $\mathrm{HH} \sigma^{\circ}$ for selected pixels of a lake that freezes to the bed in late winter. The solid black line represents a best fit (linear regression) for the available samples. 
In order to quantify the changes in $\sigma^{\circ}$, an initial assessment of the incidence angle and polarization effects was performed. Analysis of ASAR and RADARSAT $-2 \sigma^{\circ}$ in relation to incidence angles during 2010 shows high oscillations of $\sigma^{\circ}$ values in images acquired on the same date or one day apart. Results also show that $\sigma^{\circ}$ differences at similar incidence angle ranges are fairly constant for images acquired on the same date. For example, for same-day and -orbit (ascending/descending) ASAR and RADARSAT-2 acquisitions, with differences between incidence angle ranging from $1.17^{\circ}$ to $7.71^{\circ}, \sigma^{\circ}$ fluctuations were small and ranged from 1 to $3 \mathrm{~dB}$. When differences in the incidence angle of acquisitions from the two sensors are greater than $8^{\circ}$, differences in $\sigma^{\circ}$ range from 3 to $9 \mathrm{~dB}$ (Table 5).

Table 5. Same-day ASAR and RADARSAT-2 $\sigma^{\circ}$, incidence angle and orbit.

\begin{tabular}{ccccccc}
\hline Date of Acquisition & ASAR $\boldsymbol{\theta}\left(^{\circ}\right)$ & ASAR $\boldsymbol{\sigma}^{\circ}(\mathbf{d B})$ & ASAR Orbit & R-2 $\boldsymbol{\theta}\left({ }^{\circ}\right)$ & $\mathbf{R - 2} \boldsymbol{\sigma}^{\circ}(\mathbf{d B})$ & $\mathbf{R - 2}$ Orbit \\
\hline 14 February 2010 & 21.78 & -16.31 & DESC & 36.18 & -20.19 & DESC \\
03 April 2010 & 33.52 & -18.59 & DESC & 36.45 & -20.17 & DESC \\
08 May 2010 & 35.89 & -18.89 & DESC & 42.88 & -20.85 & DESC \\
24 May 2010 & 28.32 & -16.82 & ASC & 36.03 & -19.28 & ASC \\
31 May 2010 & 22.52 & -13.81 & ASC & 34.27 & -23.5 & ASC \\
21 June 2010 & 28.32 & -16.85 & ASC & 27.15 & -13.22 & ASC \\
\hline
\end{tabular}

For same-day ASAR and RADARSAT-2 images, in order to correct the differences in incidence angle between the two sensors, an adjustment of $0.9 \mathrm{~dB}$ could be applied to RADARSAT- 2 images acquired at incidence angles of $20^{\circ}-33^{\circ}$ and one of $1.6 \mathrm{~dB}$ to images acquired at incidence angles of $33^{\circ}-46^{\circ}$. These values were calculated based on the sum of same-day ASAR and RADARSAT-2 power over the selected ROI, sum that was divided by two and then converted to $\sigma^{\circ}$. Considering that lake surface conditions (e.g., ice thickness, transition from a floating to a grounded ice cover, transition from open water to an ice cover and vice versa) change in time and that consequently the bulk dielectric properties of the lake surface also change and affect in turn the surface and/or volume scattering, this correction is highly recommended to only be applied to same-/consecutive-day images. Applying the same approach when images are acquired at intervals of 2-12 days is only appropriate when knowledge of ice conditions confirms that ice conditions remain constant and thus the observed change in $\sigma^{\circ}$ is solely from surface scattering as a result of changing SAR incidence angle. Without additional information, applying an incidence angle correction to ASAR and RADARSAT-2 images that are acquired at intervals greater than two days would have to assume that lake surface conditions remain constant between the observations. However, in order to evaluate the possibility of using this approach, this hypothesis was assumed and differences in incidence angle were corrected by $0.9 \mathrm{~dB}$ for RADARSAT- 2 images acquired at incidence angles of $20^{\circ}-30^{\circ}$ and by $1.6 \mathrm{~dB}$ for RADARSAT- 2 images acquired at incidence angles of $30^{\circ}-46^{\circ}$ (Figure 11).

Results show that based on the hypothesis that surface conditions remain constant between the ASAR and RADARSAT-2 observations, applying an incidence angle correction calibrates the two datasets and has the potential to improve detection of important lake-ice events. However, if this correction is applied, the thresholds for detection of FO, MO and WCI dates using the RADARSAT-2 data need to be adjusted accordingly.

Evaluation of an ASAR descending-pass image (38.4 incidence angle) and a RADARSAT-2 ascendingpass image (36.03 ${ }^{\circ}$ incidence angle) acquired on 24 May 2010 show a difference in $\sigma^{\circ}$ of $2.08 \mathrm{~dB}$. If the 
calculated incidence angle correction of $1.6 \mathrm{~dB}$ is applied, it can be derived that the change in $\sigma^{\circ}$ is only of $0.48 \mathrm{~dB}$. A more comprehensive analysis of orbit effects on $\sigma^{\circ}$ was not possible in this study given that these were the only available overlapping ASAR and RADARSAT-2 images acquired at similar incidence angles and at different orbit modes. This suggests that $\sigma^{\circ}$ differences for the selected ROIs are likely to be related to differences in incidence angle rather than the orbit mode.

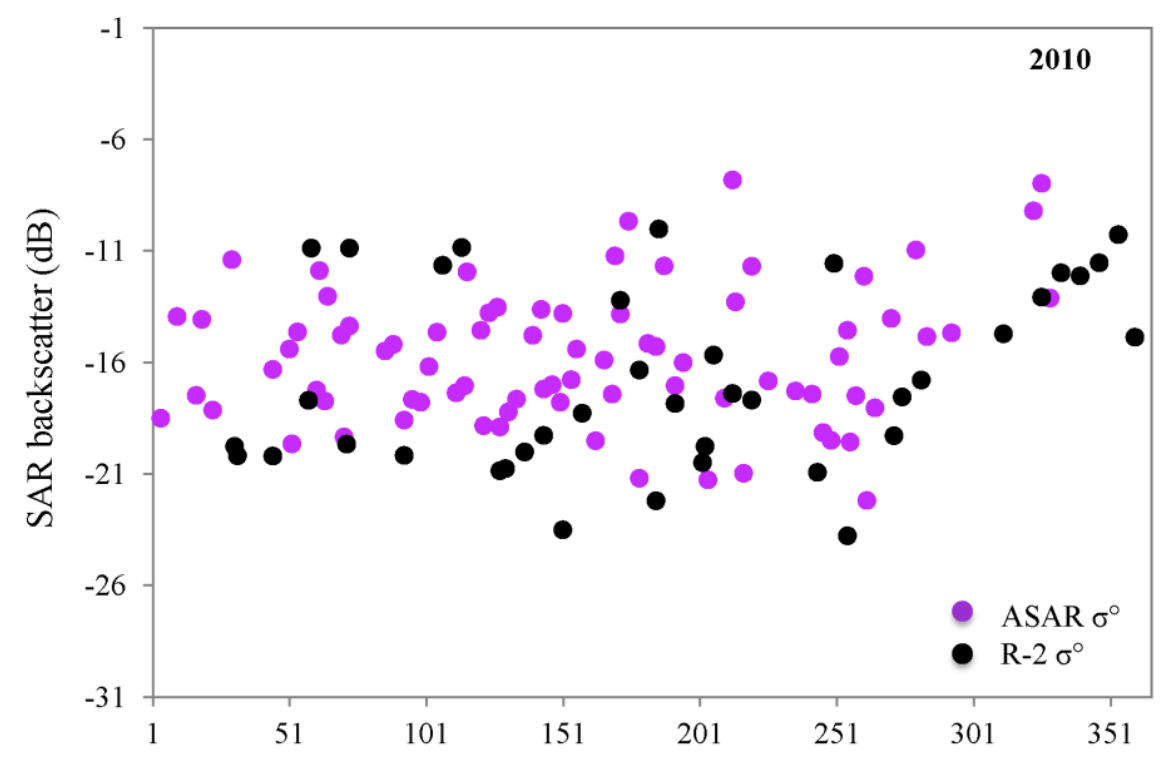

Day of the Year (DOY)

(a)

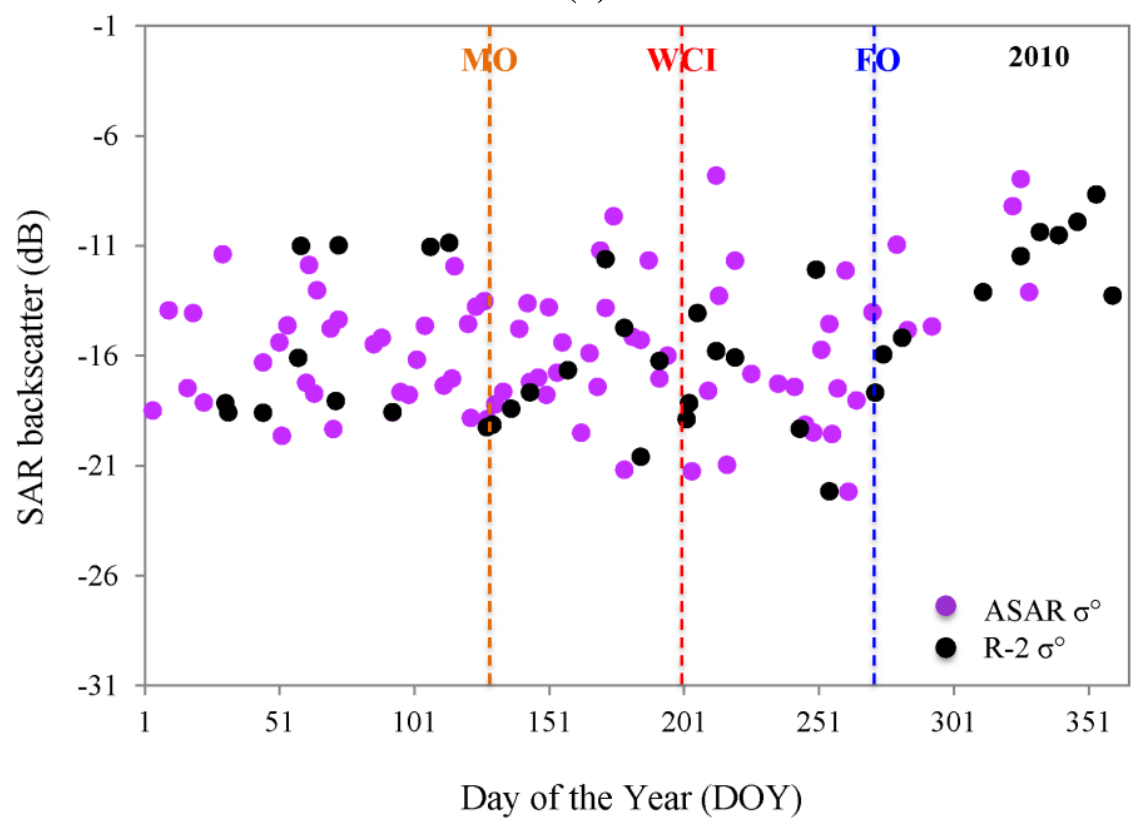

(b)

Figure 11. (a) Uncorrected temporal evolution of ASAR and RADARSAT-2 backscatter over a lake that freezes to the bed, near Barrow, Alaska) in 2010. (b) Incidence-angle corrected temporal evolution of ASAR and RADARSAT-2 backscatter over a lake that freezes to the bed, near Barrow, Alaska) in 2010. Freeze onset, melt onset and water-clear-of-ice dates are also shown. 
These results show that the oscillations and magnitude of $\sigma^{\circ}$ variations is a function of changes in lake surface type (ice versus open water) and differences in incidence angle. Although incidence angle correction improves detection of lake-ice events by combing acquisitions from two SAR satellites, the changing ice conditions (e.g., transition from floating to grounded ice) between images acquired at more than 1-2 day differences may justify the differences in $\sigma^{\circ}$.

However, considering the numerous unknown parameters (e.g., ice cover type, ice thickness, wind conditions, the timing of transition from a grounded ice cover to initiation of melt) and the limited same-day ASAR and RADARSAT-2 acquisitions, calculation of an incidence angle correction for such a diversified data set is difficult and therefore not applied to the full dataset analyzed for the detection of ice dates in this paper. Nevertheless, this is a topic that warrants further investigation in light of new and upcoming C-band satellite missions.

\section{Conclusions}

The primary objective of this study was to investigate the potential of high temporal frequency C-band $\sigma^{\circ}$ from combined ASAR and RADARSAT-2 observations for detection of ice phenological events, such as the beginning, start and end of the ice season. Results show that C-band SAR is generally suitable for discrimination between ice and open water; however, some limitations were also identified.

SAR observations fall within similar ranges with CLIMo simulations, particularly for the FO dates of 2009-2011, when increased satellite observations were available, and for the WCI dates during all years of the time series. Detection of freeze and that of a continuous ice cover onset is challenging because of the wind effect (speed and direction) on radar $\sigma^{\circ}$ during freeze-up or because of the similar $\sigma^{\circ}$ signal from the newly formed ice and that of open water. Moreover, the presence or absence of bubbles, and/or locally drifted snow, resulting in high oscillations of radar returns, complicate FO and complete-freeze-over detection on the shallow lakes examined in this study.

Limitations for $\mathrm{MO}$ are related to the intensity of $\sigma^{\circ}$ signal from the ice cover of the shallow lakes that freeze to the bottom during winter. Lakes on the North Slope of Alaska are in their majority shallow lakes, with depths ranging from under $1.4 \mathrm{~m}$ (7\% of the lakes) to $1.4-1.5 \mathrm{~m}$ (60\% of the lakes) and 1.5-2.2 (10\% of the lakes). The remaining 23\% represents lakes that may be deeper than $2.2 \mathrm{~m}$ [12]. By late winter (end of April), many of these lakes freeze to the lakebed [16]. The $\sigma^{\circ}$ signal from lakes frozen to the lakebed is already low prior to onset of melt. Identifying the differences in $\sigma^{\circ}$ returns from grounded ice poses its challenges. The differences in lake-ice cover types (grounded versus floating ice) would eventually result in threshold values close or below the noise floor, or MO may be mistaken with WCI conditions for lakes frozen to the lakebed. A more fitting approach would be to perform image segmentation of datasets acquired in late winter, determine the lakes with a floating or grounded ice cover, and according to the derived segmentation results, apply a lower threshold on the $\sigma^{\circ}$ from lakes frozen to the lakebed in order to detect more accurately the start of the melt season for these lakes.

This was the first study of its kind to evaluate the performance of C-band $\sigma^{\circ}$ from the combination of two different SAR sensors to derive important lake-ice dates. Overall, this work showed the potential of high temporal frequency SAR for detection of lake-ice events, within an accuracy of 2-5 days. In order to maximize observations, this study used all available data. However, limitations exist and further improvements are needed in order to increase the accuracy of this method. Future work in using the analysis 
of the $\sigma^{\circ}$ temporal evolution from the existing dual-polarized C-band sensors should investigate in more detail the effect of incidence angle on radar $\sigma^{\circ}$. The use of reliable wind data (from weather stations or spaceborne altimeters) is also recommended in interpretation of C-band $\sigma^{\circ}$ for detection of ice events. Moreover, use of polarimetric parameters from RADARSAT-2 observations could improve detection of FO [22].

The newly launched Sentinel-1A, and the follow-up Sentinel-1B mission, with a spatial resolution of $20 \times 40 \mathrm{~m}$ in extra-wide swath mode, and the upcoming RADARSAT constellation, will not only continue the historical records of the ERS-1/2 and ENVISAT (C-band) missions but will also provide more frequent acquisitions that will improve timing estimates of ice phenology parameters. In addition, the multi-spectral Sentinel-2A/B missions, with a spatial resolution of 10-20 $\mathrm{m}$ in visible to mid-infrared bands are planned for launch in 2015 and 2016. These missions will deliver optical data that will increase the frequency of acquisitions (every 1-2 days at high latitudes in cloud-free conditions) and be an invaluable complement to SAR observations of lake ice. Combining observations from multiple missions complies with the Integrated Global Observing Strategy [24] requirements for comprehensive global monitoring and the possible delivery of an operational product, with nearly daily observations.

\section{Acknowledgments}

Financial assistance was provided through a Discovery Grant from the Natural Sciences and Engineering Research Council of Canada (NSERC) to Claude Duguay. Great support was provided by the Grid Processing on Demand (GPOD) team of the European Space Agency (ESA) led by Roberto Cuccu and Giovanni Sabatini through the pre-processing of the ASAR images. The authors would like to thank Luis Veci (Array Systems Computing) and Chris Stewart (ESA) for technical support with processing of the RADARSAT-2 data. The ASAR scenes were provided by ESA. RADARSAT-2 data and products, MacDonald $^{\odot}$, Dettwiler and Associates Ltd., 2009-2011, All Rights Reserved. RADARSAT is an official mark of the Canadian Space Agency. MODIS-Aqua and -Terra Land Surface Temperature were provided by the National Aeronautics and Space Administration (NASA) through the Land Processes Distributed Active Archive Center (LP DAAC).

\section{Author Contributions}

The final format of this article is a result of collaboration with all listed co-authors. All presented work is the result of a close collaboration with Claude Duguay who provided continuous support, advice and valuable comments through this research. MODIS LIST/LWST data was processed by Homa Kheyrollah Pour. CLIMo data and outputs used and prompt assistance with model results were provided by Laura Brown (University of Toronto).

\section{Conflicts of Interest}

The authors declare no conflict of interests. 


\section{References}

1. Sellmann, P.V.; Brown, J.; Lewellen, H.; McKim, H.; Merry, C. The Classification and Geomorphic Implications of Thaw Lakes found in Arctic Alaska; Research Report 344; U.S. Army Cold Regions Research and Engineering Laboratory: Hanover, NH, USA, 1975.

2. Li, S.; Jeffries, M.; Morris, K. Mapping the bathymetry of shallow tundra lakes using InSAR techniques. Proc. IGARSS 2000, 5, doi: 10.1109/IGARSS.2000.858365

3. Surdu, C.M.; Duguay, C.R.; Brown, L.C.; Fernández Prieto, D. Response of ice cover on shallow lakes of the North Slope of Alaska to contemporary climate conditions (1950-2011): Radar remote sensing and numerical modeling data analysis. Cryosphere 2014, 8, 167-180.

4. Screen, J.A.; Simmonds, I. The central role of diminishing sea ice in recent Arctic temperature amplification. Nature 2010, 464, 1334-1337.

5. IPCC. Climate change 2013: The Physical science Basis. Contribution of Working Group I to the Fifth Assessment Report of the Intergovernmental Panel on Climate Change; Stocker, T.F., Qin, D., Plattner, G.-K., Tignor, M., Allen, S.K., Boschung, J., Nauels, A., Xia, Y., Bex, V., Midgley, P.M., Eds.; Cambridge U. Press: New York, NY, USA, 2013; p. 1535, doi:10.1017/CBO9781107415324.

6. AMAP. Snow, Water, Ice and Permafrost in the Arctic (SWIPA) 2011; Arctic Monitoring and Assessment Programme (AMAP): Oslo, Norway, 2011.

7. Brown, R.; Derksen, C.; Wang, L. A multi-data set analysis of variability and change in Arctic spring snow cover extent, 1967-2008. J. Geophys. Res.: Atmos. 2010, 115, doi:10.1029/2010JD01397.

8. Arp, C.D.; Jones, B.M.; Urban, F.E.; Grosse, G. Hydrogeomorphic processes of thermokarst lakes with grounded-ice and floating-ice regimes on the Arctic coastal plain, Alaska. Hydrol. Process. 2011, 25, 2422-2438, doi:10.1002/hyp.8019

9. Ling, F.; Zhang, T. Numerical simulation of permafrost thermal regime and talik development under shallow thaw lakes on the Alaskan Arctic Coastal Plain. J. Geophys. Res. 2003, 108, doi:10.1029/2002JD003014

10. Stephenson, S.R.; Smith, L.C.; Agnew, J.A. Divergent longterm trajectories of human access to the Arctic. Nat. Clim. Chang. 2011, 1, 156-160, doi:10.1038/NCLIMATE112.

11. Hinkel, K.M.; Zheng, L.; Yongwei, S.; Evan, A. Regional lake ice meltout patterns near Barrow, Alaska. Polar Geogr. 2012, 35, 1-18.

12. Jeffries, M.O.; Morris, K.; Liston, G.E. A method to determine lake depth and water availability on the north slope of Alaska with spaceborne imaging radar and numerical ice growth modelling. Arctic 1996, 49, 367-374.

13. Duguay, C.R.; Prowse, T.D.; Bonsal, B.R.; Brown, R.D.; Lacroix, M.P.; Ménard, P. Recent trends in Canadian lake ice cover. Hydrol. Process. 2006, 20, 781-801.

14. Palecki, M.A.; Barry, R.G. Freeze-up and break-up of lakes as an index of temperature changes during the transition seasons: A case study for Finland. J. Clim. Appl. Meteorol. 1996, 25, 893-902.

15. Arp, C.D.; Jones, B.M.; Grosse, G. Recent lake ice-out phenology within and among lake districts of Alaska, USA. Limnol. Oceanogr. 2013, 58, 2013-2028, doi:10.4319/1o.2013.58.6.2013.

16. Jeffries, M.O.; Morris, K.; Weeks; W.F.; Wakabayashi, H. Structural and stratigraphic features and ERS 1 synthetic aperture radar backscatter characteristics of ice growing on shallow lakes in NW Alaska, winter 1991-1992. J. Geophys. Res. 1994, 99, 22459-22471. 
17. Duguay, C.R.; Pultz, T.J.; Lafleur, P.M.; Drai, D. RADARSAT backscatter characteristics of ice growing on shallow sub-arctic lakes, Churchill, Manitoba, Canada. Hydrol. Process. 2002, 16, 1631-1644.

18. Duguay, C.R.; Lafleur, P.M. Determining depth and ice thickness of shallow subarctic lakes using spaceborne optical and SAR data. Int. J. Remote Sens. 2003, 24, 475-489.

19. White, D.M.; Prokein, P.; Chambers, M.K.; Lilly, M.R.; Toniolo, H. Use of synthetic aperture radar for selecting Alaskan lakes for winter water use. J. Am. Water Resour. Assoc. 2008, 44, 276-284.

20. Cook, T.L.; Bradley, R.S. An analysis of past and future changes in the ice cover of two high-Arctic lakes based on synthetic aperture radar (SAR) and Landsat imagery. Arct. Antarct. Alp. Res. 2010, 42, 9-18.

21. Geldsetzer, T.; Van Der Sanden, J.J. Identification of polarimetric and nonpolarimetric C-band SAR parameters for application in the monitoring of lake ice freeze-up. Can. J. Remote Sens. 2013, 39, 263-275.

22. Geldsetzer, T.; Van Der Sanden, J.J.; Brisco, B. Monitoring lake ice during spring melt using RADARSAT-2 SAR. Can. J. Remote Sens. 2010, 36, S391-S400.

23. Howell, S.E.L.; Brown, L.C.; Kang, K.-K.; Duguay, C.R. Variability in ice phenology on Great Bear Lake and Great Slave Lake, Northwest Territories, Canada, from SeaWinds/QuikSCAT: 2000-2006. Remote Sens. Environ. 2009, 113, 816-834.

24. IGOS. Integrated Global Observing Strategy Cryosphere Theme Report-For the Monitoring of Our Environment from Space and from Earth; World Meteorological Organization: Geneva, Switzerland, 2007; WMO/TD-No. 1405, p. 100.

25. Mellor, J. Bathymetry of Alaskan Arctic Lakes: A Key to Resource Inventory with Remote Sensing Methods. Ph.D. Thesis, Institute of Marine Science, University of Alaska, Fairbanks, AK, USA, May 1982.

26. Hall, D.K.; Fagre, D.B.; Klasner, F.; Linebaugh, G.; Liston, G.E. Analysis of ERS 1 synthetic aperture radar data of frozen lakes in northern Montana and implications for climate studies. J. Geophys. Res. 1994, 99, 22473-22482.

27. Morris, K.; Jeffries, M.O.; Weeks, W.F. Ice processes and growth history on Arctic and sub-arctic lakes using ERS-1 SAR data. Polar Rec. 1995, 31, 115-128.

28. Duguay, C.R.; Pultz, T.J.; Lafleur, P.M.; Drai, D. RADARSAT backscatter characteristics of ice growing on shallow sub-arctic lakes, Churchill, Manitoba, Canada. Hydrol. Process. 2002, 16, 1631-1644.

29. Sobiech, J.; Dierking, W. Observing lake- and river-ice decay with SAR: advantages and limitations of the unsupervised k-means classification approach. Ann. Glaciol. 2013, 54, doi:10.3189/2013AoG62A037

30. Ménard, P.; Duguay, C.R.; Flato, G.M.; Rouse, W.R. Simulation of ice phenology on Great Slave Lake, Northwest Territories, Canada. Hydrol. Process. 2002, 16, 3691-3706.

31. Duguay, C.R.; Flato, G.M.; Jeffries, M.O.; Ménard, P.; Morris, K.; Rouse, W.R. Ice-cover variability on shallow lakes at high latitudes: Model simulations and observations. Hydrol. Process. 2003, 17, 3465-3483. 
32. Jeffries, M.O.; Morris, K.; Kozlenko, N. Ice characteristics and processes, and remote sensing of frozen rivers and lakes. In Remote Sensing in Northern Hydrology: Measuring Environmental Change; Duguay, C.R., Pietroniro, A., Eds.; American Geophysical Union: Washington, DC, USA, 2005; pp. 63-90.

33. Brown, L.C.; Duguay, C.R. A comparison of simulated and measured lake ice thickness using a shallow water ice profiler. Hydrol. Process. 2011, 25, 2932-2941.

34. Sturm, M.; Liston, G.E. The snow cover on lakes of the Arctic Coastal Plain of Alaska, USA. J. Glaciol. 2003, 49, 370-380.

35. Kheyrollah Pour, H.; Duguay, C.R.; Martynov, A.; Brown, L.C. Simulation of surface temperature and ice cover of large northern lakes with 1-D models: A comparison with MODIS satellite data and in-situ measurements. Tellus A 2012, 64, doi:10.3402/tellusa.v64i0.17614

36. Kheyrollah Pour, H.; Duguay, C.R.; Solberg, R.; Rudjord, Ø. Impact of satellite-based lake surface observations on the initial state of HIRLAM. Part I: Evaluation of remotely-sensed lake surface water temperature observations. Tellus A 2014, 66, doi:10.3402/tellusa.v66.21534.

37. Duguay, C.R.; Soliman, A.; Hachem, S.; Saunders, W. Circumpolar and Regional Land Surface Temperature (LST) with Links to geotiff Images and netCDF Files (2007-2010); University of Waterloo: Waterloo, ON, Canada, 2012; doi:10.1594/PANGAEA.775962.

38. Soliman, A.; Duguay, C.R.; Saunders, W.; Hachem, S. Pan-arctic land surface temperature from MODIS and AATSR: Product development and intercomparison. Remote Sens. 2012, 4, 3833-3856, doi:10.3390/rs4123833

39. Cheng, B.; Vihma, T.; Rontu, L.; Kontu, A.; Kheyrollah Pour, H.; Duguay, C.R.; Pulliainen, J. Evolution of snow and ice temperature, thickness and energy balance in Lake Orajärvi, northern Finland. Tellus A 2014, 66, doi.org/10.3402/tellusa.v66.21564

40. Brown, L.C.; Duguay, C.R. The response and role of ice cover in lake-climate interactions. Prog. Phys. Geog. 2010, 34, 671-704.

41. Jeffries, M.O.; Morris, K. Some aspects of ice phenology on ponds in central Alaska, USA. Ann. Glaciol. 2007, 46, 397-403.

42. Ashton, G.D. River and Lake Ice Engineering; Water Resource Publications: Littleton, CO, USA, 1986; p. 485.

43. Jensen, O.P.; Benson, B.J.; Magnuson, J.J.; Card, V.M.; Futter, M.N.; Soranno, P.A. Spatial analysis of ice phenology trends across the Laurentian Great Lakes region during a recent warming period. Limnol. Oceanogr. 2007, 52, 2013-2026.

44. Ulaby, F.T.; Moore, R.K.; Fung, A.K. Microwave Remote Sensing: Active and Passive, Vol. III: From Theory to Applications; Artech House, Inc.: Norwood, MA, USA, 1986; p. 1097.

45. Nghiem, S.V.; Leshkevich, G.A. Satellite SAR remote sensing of Great Lakes ice cover, Part 1. Ice backscatter signatures at C-band. J. Great Lakes Res. 2007, 33, 722-735.

(C) 2015 by the authors; licensee MDPI, Basel, Switzerland. This article is an open access article distributed under the terms and conditions of the Creative Commons Attribution license (http://creativecommons.org/licenses/by/4.0/). 